Portland State University

PDXScholar

1970

\title{
Investigation of the alpha-sub-gamma phase in alnico 6
}

Cortez Samuel

Portland State University

Follow this and additional works at: https://pdxscholar.library.pdx.edu/open_access_etds

Part of the Atomic, Molecular and Optical Physics Commons, Biological and Chemical Physics Commons, and the Materials Chemistry Commons

Let us know how access to this document benefits you.

\section{Recommended Citation}

Samuel, Cortez, "Investigation of the alpha-sub-gamma phase in alnico 6" (1970). Dissertations and Theses. Paper 1473.

https://doi.org/10.15760/etd.1472

This Thesis is brought to you for free and open access. It has been accepted for inclusion in Dissertations and Theses by an authorized administrator of PDXScholar. Please contact us if we can make this document more accessible: pdxscholar@pdx.edu. 
AN ABSTRACI OF THE THESIS OF Cortaz Smual for the Haster of Soince In Fyysics presented September 4, 1970.

Title: Investigation of the Alpha-Sub-Ganna Frase in Alnico 6. AFPRCVED BY MENRERS OF THE THESIS COMITTEE:

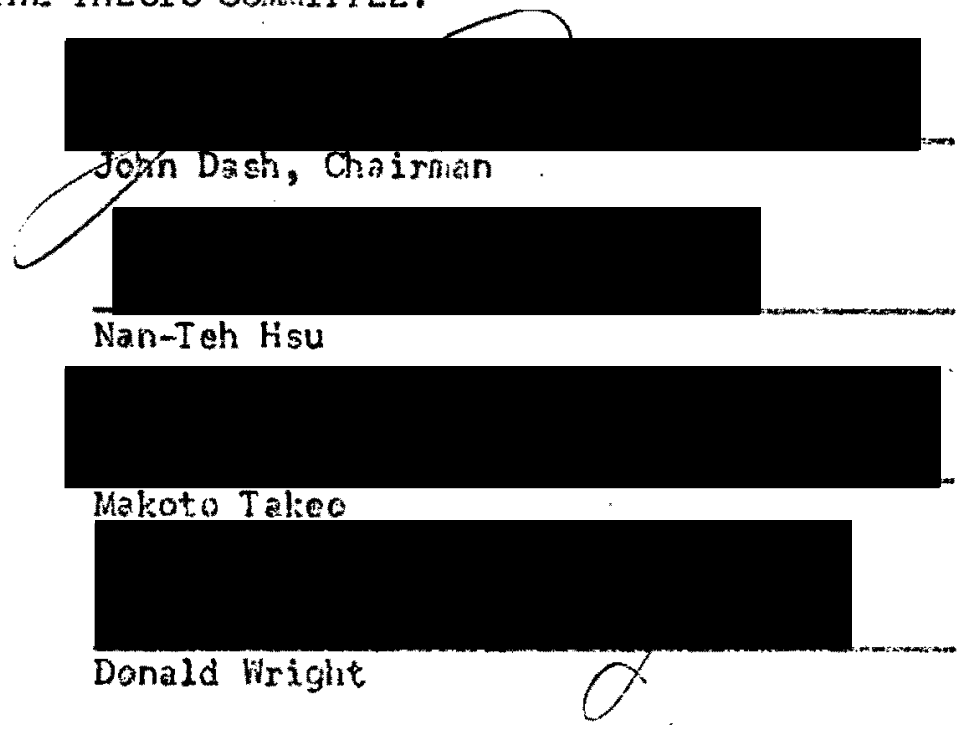

The purpose of this research project was to study the $\alpha_{\gamma}$ plase in Alnico 6. Other phases were studied for comparison. Also tho effect of an applied magnetic field on the formation os the of Thase was investigated.

Three single crystals of Alnico 6 were heat treated for ono hour-one at $1250^{\circ} \mathrm{C}$, one at $1000^{\circ} \mathrm{C}$, and one at $800^{\circ} \mathrm{C}$-and waterwgueriched. The nicrostructure of each sample was abserved with the optical microw scope, and $x$-ray diffxaction patterns vere taken to determine the crystal structure of the phases present.

Severol single cryotil surples of Alnico 6 were hat treated at $1000^{\circ} \mathrm{C}$ and furnace-cooled. Some of the samplas ve heat treated and 
furnace-cooled in the presence of an applied magnetic field of about 5000 de, and the others were heat treated and furnace-cooled without an applied magnetic field. Each set of samples were electrothinned, and the microstructure of the $\alpha_{\gamma}$ and $\alpha_{1}+\alpha_{2}$ phases was studied using the electron microscope. Electron diffraction patterns and electron micrographs were taken from $\alpha_{r}$ regions and $\alpha_{1}+\alpha_{2}$ regions of each sample. By a combination of X-ray and electron diffraction, it was determined that the crystal structure of the $\alpha, \alpha_{1}, \alpha_{2}$, and $\alpha_{\gamma}$ phases is body-centered cubic, with a lattice parameter of $2.87 \AA$. Electron diffraction showed that the crystal structure of the conbined $\alpha_{1}+\alpha_{2}$ phases is ordered body-centered cubic, and that the lattices of these two phases are coherent. Other investigators have found that only the $\alpha$, phase is ordered in Alnico 5 and Alnico 8, and this is believed to be the case in Alnico 6 also. Electron diffraction showed the $\alpha_{\gamma}$ phasa to be ordered, with the degres of ordering less than that. in the $\alpha$, phase.

Some difference was noted between the $\alpha_{\gamma}$ phase formed with a magnotic field and that formed without a manctic field. The $\alpha_{\gamma}$ formed with a magnetic finld showed twinning and sorne small lattice rotations, while that forred without a field did not. The reason for this is not known. 


\section{INVEST IGATION OF THE ALPHA-SUB-GAMMA \\ PHASE IN ALNICO 6}

\section{by}

CORTEZ SAMUEL

A thesis submittad in partial fulfillment of the requirements for the degree of

\section{MASTER OF SCIENCE \\ in \\ PHYSICS}

Portland State University

1970 
TO THE OFFICE OF GRADUATE STUDIES:

The neabers of the Comalttee approve the thesls of Corter Sanuel presented Septenber 4, 1970.

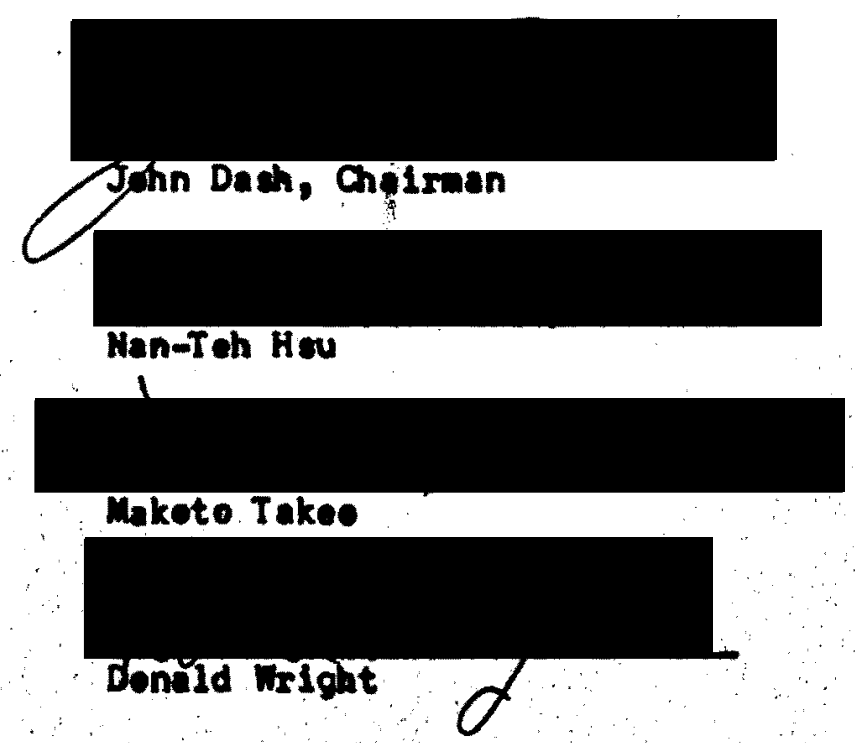

APPROVED,

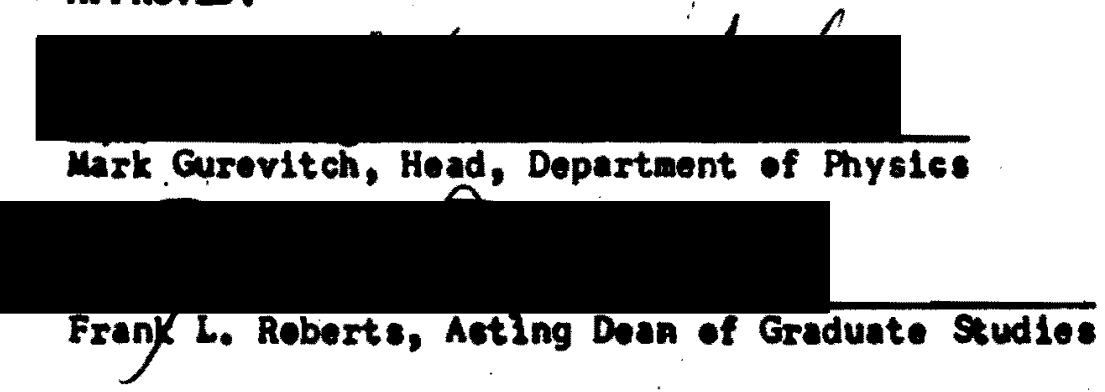

September 8, 1970 


\section{ACKNOWLEDGMENT S}

The author is grateful to his adviser, Dr. John Dash, for his guidance throughout the research project. Dr. Dash provided the samples of Alnico 6; took the electron micrographs and electron diffraction patterns; and was an excellent source of information for the theory and experimental procedures.

Financial support was provided by the Tektronix Foundation Fellowship in Materials Science and by a grant from Research Corporation. This financial assistance made this work possible, and the author is grateful for the generosity of these organizations. 
TABLE OF CONTENT S

PAGE

ACKNOWLEDGMENTS .......................

LIST OF TABLES ......................

IIST OF FIGURES .......................

vil

CHAPTER

I INTRODUCT ION AND REVIEW OF THE LITERATURE . . . . 1

Phase Relations ................. 2

$\alpha_{1}+\alpha_{2}$ Phases................ 3

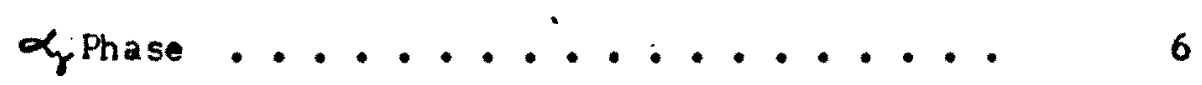

II DESCRIPTION OF THE PROBLEM ............. 9

III METHODS AND TECHNIQUES . . . . . . . . . . 11

Samples Studied by Optical Microscopy and

X-ray Diffraction ............

Samples Studied by Electron Microscopy and

Electron Diffraction........... 11

Heat Treatment ............. 11

Magnetic Annealing Furnace........ 14

Electrothinning ........... 15

IV EXPERIMENTAL OBSERVATIONS . . . . . . . . . 18

Optical Microscopy and X-ray Diffraction .... 18

Electron Microscopy and Electron Diffraction . . 24

Samples Heat Ireated without a magnetic

Field .............. 24

Samples Heat Treated with a magnetic

Field ............... 
V DISCUSSION OF THE RESULTS . . . . . . . .

Conclusions . . . . . . . . . .

Suggestiens for Further Study . . . . . . 


\section{LIST OF TABLES}

TABLE

PAGE

I Phase Relations of Alnico 8 Alloys ....... 


\section{LIST OF FIGURES}

FIGURE

PAGE

1 The effect of the $\alpha_{\gamma}$ phase on the magnetic properties of Alnico 8 samples .............. 8

2 Photograph of the magnetic annealing furnace positioned between the pole pieces of the electromagnet ................. 13

3 Schematic diagram of the electrothinning circuit . . 16

4 Dark field optical micrograph of the $\alpha$ phase of an Alnice 6 sample heated for $1 \mathrm{hr}$ at $1250^{\circ} \mathrm{C}$ and water-quenched $\ldots . . . . . . . . . . .19$

$5 \quad X$-ray diffraction pattern of the $\alpha$ phase ..... 19

6 Dark field optical micrograph of the $\alpha$ and $\alpha_{\gamma}$ phases of a sample of Alnico 6 heated for $1 \mathrm{hr}$ at $1000^{\circ} \mathrm{C}$ and water-quenched .......... 21

$7 \quad X$-ray diffraction pattern of the $\alpha$ and $\alpha_{\gamma}$ phases ........................ 21

8 Dark field optical micrograph of the $\alpha_{1}$ and $\alpha_{2}$ phases of an Alnico 6 sample heated for $\mathrm{l} \mathrm{hr}$ at

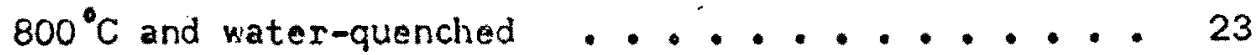

$9 \quad x$-ray diffraction pattern of the $\alpha_{1}$ and $\alpha_{2}$

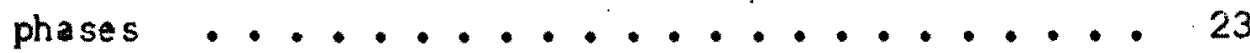

10 Bright field optical micrograph of a sample heat treated withont a magnetic field and furnace-cooled . 25 
11 Bright field optical micrograph of a sample heat treated with a magnetic field and furnace-cooled . . 25

12 Electron micrograph showing the $\alpha_{\gamma}$ phase and the $\alpha_{1}+\alpha_{2}$ phases of a sample heat treated without a magnetic fleld and furnace-cooled . . . . 26

13 Electon diffraction pattern of the $\alpha_{1}+\alpha_{2}$ phases ................ 28

14 Electron diffraction pattern of the $\alpha_{\gamma}$ phase .... 28

15 Electron micrograph showing the (100) plane

of a sample heat treated without a magnetic field ... 30

16 Electron diffraction pattern of the $\alpha_{1}+\alpha_{2}$ phases .................. 31

17 Electron diffraction pattern of the $\alpha_{\gamma}$ phase .... 31

18 Electron micrograph of a sample heat treated with a magnetic field and furnace-cooled ....... 33

19 Electron diffraction pattern of the $\alpha_{1}+\alpha_{2}$ phases ................ . . 34

20 Electron diffraction pattern of the $\alpha_{\gamma}$ phase . . . 34

21. Electron micrograph of a sample heat treated with a magnetic field and furnace-cooled ...... 35

22 Electron diffraction pattern of the $\alpha_{1}+\alpha_{2}$ phases .................. 35

23 Electron diffraction pattern of the $\alpha_{\gamma}$ phase ... 35

24 Electron micrograph of the $\alpha_{\gamma}$ phase ........ 37

25. Election diffraction pattern of the $\alpha_{\gamma}$ phase . . . 37 
26 Electron micrograph of the $\alpha_{1}+\alpha_{2}$

phases and three unknom particles ........ 40

27a Electron diffraction pattern of the $\alpha_{1}+\alpha_{2}$ phases ...................... 40

27b Electron diffraction pattern of the $\alpha_{1}+\alpha_{2}$ phases and one of the unkriown particles.......40 


\section{CHAPTER I}

\section{INTRODUCTION AND REVIEW OF THE LITERATURE}

Alnico alloys are one of the most important single group of materials used for permanent magnets. These materials are alloys of iron, nickel, cobalt, copper, and aluminum, and have a wide range of excellent magnetic properties. The groundwork was laid by Mishima in 1931 by demonstrating that a certain group of Al-Ni-Fe alloys was suitable for permanent magnets (1). Later the magnetic properties were improved by the addition of cobalt and copper to form Alnico pernanent magnets.

Alnico 5 is one of the most important comnercial alloys of this family. This alloy contains $51 \% \mathrm{Fe}, 24 \% \mathrm{Co}, 14 \% \mathrm{Ni}, 8 \% \mathrm{Al}$, and $3 \% \mathrm{Cu}$ by welght. An energy product $(\mathrm{BH})_{\max }=4.5-5.0 \times 10^{6} \mathrm{G}$ oe and a coercive force $H_{c}=600-530$ Oe (1) are indicative of the excellent magnetic properties of these alloys when theyare heat treated in a magnetic field. These nagnetic properties are obtained for a polycrystalline sample; properties for a single crystal sample are improved significantly.

These Alnico alloys have cubic structure. Then a magnetic field of about 1000 oe is applied along a (100) direction of a single crystal during heat treatment, values as high as $8.7 \times 10^{6} \mathrm{G}$ oe for the maximum energy product and 760 De for the coercive force have been realized in Alnico 5 alloys (2). 
It has been shown that the limited addition of titanium raises the coercive forco of Alnico alloys (3). A crystal-oriented sample of Alnico 8 (containing $35 \% \mathrm{Fe}, 34.8 \% \mathrm{Co}, 14.9 \% \mathrm{Ni}, 7.5 \% \mathrm{Al}, 2.4 \% \mathrm{Cu}$, and $5.4 \% \mathrm{Ti}$ by weight) was developed by Naastepad (4), with a maximum energy product of about $13 \times 10^{6} \mathrm{G}$ oe and a coercive force of about 1520 De.

\section{PHASE RELATIONS}

Alnico 5 may serve as an example of the phase relations of the Alnico alloy group. High temperature X-ray diffraction by Koch, v. d. Steeg, and de Vos (4) showed that this alloy exists as an ordered bcc phase $(\alpha)$ above $1200^{\circ} \mathrm{C}$ with a lattice parameter of $2.87 \AA$. Between $1200^{\circ} \mathrm{C}$ and $850^{\circ} \mathrm{C}$ the $\alpha$ phase is in equilibriug with a fcc phase $\left(\gamma_{1}\right)$. Below $850^{\circ} \mathrm{C}$ the $\gamma_{1}$ phase transforms spontaneously to a new bec phase $\left(\alpha_{\gamma}\right)$ which has the same spacing as the $\alpha$ phase, and the $\alpha$ phase transforms to two new bec phases $\left(\alpha_{1}\right.$ and $\left.\alpha_{2}\right)$. The $\alpha_{1}$ phase is ordered and has the same spacing as the $\alpha$ phase, but the $\alpha_{2}$ phase has no ordering and has a slightly larger spacing than the $\alpha$ phase. After tempering for about two months at $600^{\circ} \mathrm{C}$ a new fcc phase $\left(\gamma_{2}\right)$ was observed.

Alnico 8 has the same phases as Alnico 5, although the temperature ranges and lattice parameters differ somewhat. Table I gives the phase relations of an Alnico 8 alloy containing $35.5 \% \mathrm{Fe}, 34 \% \mathrm{Co}, 14.5 \% \mathrm{Ni}$, $7 \% \mathrm{Al}, 4 \% \mathrm{Cu}$, and $5 \% \mathrm{TI}$ by welght (4). No information about the spacing of the $\alpha_{y}$ phase was given by the authors, other than that the $\alpha_{\gamma}$ spacing was smaller than the $\alpha$, spacing to such a degree that it was fairly easy to resolve $X$-ray lines diffracted from the two phases. 
In the case of Alnico 5 no differenco was found between the spacing of $\alpha_{\gamma}$ and $\alpha_{1}$. The authors also observed that the superlattice lines in the $\alpha$ and $\alpha_{1}$ phases in the Alnico 8 alloy were much veaker than their counterparts in the Alnico 5 alloy.

\section{TABLE I}

PHASE RELATIONS OF ALNICO 8 ALLOYS (4)

\section{Temperature, ${ }^{\circ} \mathrm{C}$ Phases Present Crystal Structure}

$>1250$

$1250-845$

$$
\propto
$$

845-800

$<800$

$$
\begin{array}{ll}
\alpha+\gamma_{1} & a=2.86 \AA \\
\alpha_{1}=b c c, \text { rith super } & a=2.86 \AA \\
\alpha_{1}+\alpha_{2}+\gamma_{1} & \alpha_{2}=b c c, a=2.90 \AA \\
\alpha_{\gamma}=b c c
\end{array}
$$

$\alpha=b c c$, with superstructure,

$\alpha_{1}=$ bcc, with superstructure,

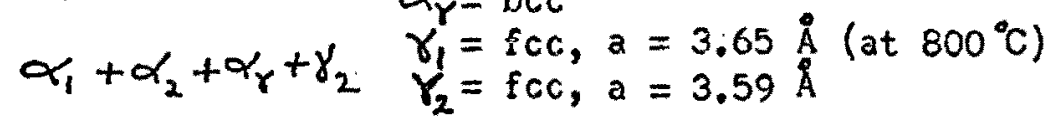

Alnico 6 has a nominal composition of $48.75 \% \mathrm{Fe}, 24 \% \mathrm{Co}, 15 \% \mathrm{NA}$, $8 \% \mathrm{Al}, 3 \% \mathrm{Cu}$, and $1.25 \% \mathrm{Ti}$ by weight (5). The nagretic properties of a polycrystalline sample (5) are indicated by a maximus energy product of about $3.65 \times 10^{5} \mathrm{GO}$ and a coercive force of $7500_{3}$. The conposition of Alritco 6 is very near that of Alrico 5, except for the addition of a small amount of titanium; therefore the phase relations of Alnico 6 are expected to be very close to those of Alnico 5, or certainly between those of Alnico 5 and Alrico 8.

$$
\text { II. } \alpha_{1}+\alpha_{2} \text { PIASES }
$$

The high coercive force of Alnico alloys is believed to be due to the precipitation of the ferromagnetic $\alpha_{2}$ phase in a matrix of weakly ferromagnetic $\alpha_{1}$ phase. This was first suggested by Stoner and Wohlfarth (6), and a precipitate was observed by Geislex (7) and Heidenreich 
and Nesbitt (8).

Again, Alnico 5 will serve as an example of the $\alpha_{1}+\alpha_{2}$ microstructure of the Alnico alloys. The microstructure has a very important difference depending on whether the heat treatment of this alloy is performed with or without a magnetic field. The two cases will be described for a single crystal sample.

The heat treatment without a magnetic field (9) consists of heating the sample to a temperature above $1200^{\circ} \mathrm{C}$ to homogenize the material, and then cooling the material at a rate of $2-5^{\circ} \mathrm{C}$ per second down to $600^{\circ} \mathrm{C}$. Then the sample is aged at $600^{\circ} \mathrm{C}$ for about 10 hours for the growth of the $\alpha_{2}$ phase. The final product is a system of rod-1ike particles of the ferromagnetic $\alpha_{2}$ phase elongated along the three $(100)$ directions of the $\alpha_{1}$ matrix.

If a magnetic field of about 1000 Os is applied along the [100] direction of the crystal during the same heat treatment, the final product is quite different. The rod-like particles are elongated only along the $[100]$ direction of the matrix. The magnetic properties in this condition are a maximum energy product of about $10 \times 10^{6} \mathrm{G}$ oe and a coercive force of $760 \mathrm{Oe}$, compared to values of $1.8 \times 10^{6} \mathrm{G}$ oe and 500 Oe for the sample heat treated without a magnetic field.

Heidenreich and Nesbitt (8) used the electron microscope to view oxide replicas of Alnico 5 samples. Their work indlcates that the slze of the partirles of the $\alpha_{2}$ precipitate at zoro aging is about $75 \times 75 \times 400 \AA$, and the particles tend to group in plate-like arrays with an average separation between arrays of rods of about $200 \AA$. For a single crystal sample heat treated with a nagnetic field along a $\langle 100\rangle$ 
direction, Heidenreich and Nesbitt visualized a structure in wich single-domain precipitate particles are parallel to single-domain matrix elements. They concluded that the precipitate is rich in cobalt and has a higher Curie temperature than the matrix, with the matrix having the larger volume.

The preferred orientation of the rod-like particles of the phase in Alnico alloys heat treated without a magnetic field is due primarily to the elastic energy. The elastic energy favors particles elongated along certain crystallographic directions, in this case along $\langle 100\rangle$ directions.

The sources of the preferred orientation of the $\alpha_{2}$ particles in Alnico alloys heat treated with a magnetic field are the elastic energy and the magnetostatic energy. These energies act in a kind of competitive process; the elastic energy favoring particles elongated along the $\langle 100\rangle$ directions, and the magnetostatic energy favoring particles elongated along the magnetic field direction. How the magnetic field is able to influence the growth of the $\alpha_{2}$ phase depends on the mechanism of precipitation. Two methods of precipitation have been proposed; classical nucleation and growth, and spinodal decomposition.

Kittel et al (9) proposed the classical nucleation and growth process. The authors suggested that the $\alpha_{2}$ phase nucleated between $900^{\circ} \mathrm{C}$ and $800^{\circ} \mathrm{C}$ as plate-like particles of about $100 \AA$ diameter and $10 \AA$ thickness. The demagnetizing energy of plates with planes perpendicular to the magnetic field was estimated as being about the order of the energy barrier for a critical nucleus, and the authors concluded that nuclei with their planes perpendicular to the fleld would be suppressed 
by a factor of $e^{-1}$ compared with those with planes parallel to the field. The magnetic field is only able to influence the morphology during the nucleation process, and the authors suggested that elastic energy and concentration gradients would continue the growth on favorable nuclei during the aging at $600^{\circ} \mathrm{C}$.

Spincdal decomposition as a mechanism of precipitation in Alnico alloys was proposed by Cahn (10). This phase change is characterized by the lowering of the free energy of an alloy by waves of composition fluctuations. Cahn showed that the magnetostatic energy favors composition waves parallel to the applied magnetic field, while the elastic energy favors waves parallel to the $\langle 100\rangle$ directions of the crystal. The elastic anisotropy is much larger than the magnetostatic anisotropy except at the Curie temperature of the initially homogeneous alloy, and at this temperature the magnetic field is most effective in influencing the precipitation of the $\alpha_{2}$ phase. The work on Alnico alloys by de Vos (11) and Dash (12) support spinodal decomposition as the mode of precipitation of the $\alpha_{2}$ phase.

\section{III. $\alpha_{\gamma}$ PHASE}

The fcc phase $\left(Y_{1}\right)$ is stable between $1200^{\circ} \mathrm{C}$ and $850^{\circ} \mathrm{C}$ in Alnico 5 alloys (4). This phase transforms to the bcc phase $\left(\alpha_{\gamma}\right)$ at temperatures below $850^{\circ} \mathrm{C}$. In Alnico 8 alloys the $\gamma_{1}$ phase is stable from $1250^{\circ} \mathrm{C}$ to a temperature believed to be somentat lower than $800^{\circ} \mathrm{C}$, where it transforms to the $\alpha_{\gamma}$ phase. If an Alnico permanent magnet alloy is not cooled fast enough from the homogenization temperature; the $\gamma_{1}$ phase forms, and subsequently the $\alpha_{Y}$ phase forms. 
The $\alpha_{Y}$ phase has a detrimental influence on the magnetic properties of an Alnico magnet. This is verified by work done on samples of Alnico 8 by Julien and Jones (13). Figure 1 shows the magnetic properties of samples of Alnico 8 as a function of the volume per cent of the $\alpha_{\gamma}$ phase (13). Although the coercive force, residual induction, and maximum energy product were affected by the presence of the $\alpha_{\gamma}$ phase; the saturation magnetization was unaffected, indicating that the $\alpha_{\gamma}$ phase has about the same magnetic moment as the matrix $\left(\alpha_{1}\right.$ and $\alpha_{2}$ combined).

Electron microprobe studies (13) indicated that the $\alpha_{\gamma}$ phase is copper-rich and cobalt-depleted, and that copper increases the $\gamma_{1}$ forming tendency of Alnico 8 alloys. Increased copper content was found to increase the $\gamma_{1}$-forming tendency in Alnico 5 alloys also (14). 

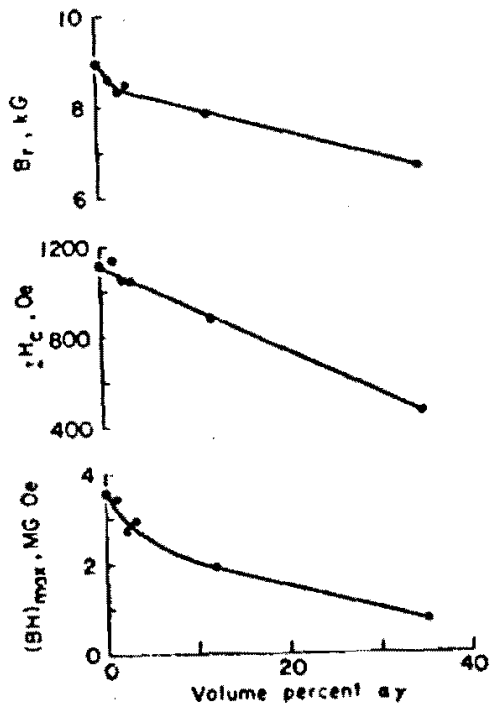

Fiqure 1 . The effect of the $\alpha_{r}$ phase on the magnetic properties of Alnico 8 samples, from the work of Julien and Jones. 


\section{CHAPTER II}

\section{DESCRIPTION OF THE PROBLEM}

Alnico. 6 is one of several of the Ainico permanent magnet alloys. As stated before the composition of Alnico 6 is very near that of Alnico 5 , except for the addition of $1.25 \%$ titanium, by weight, to Alnico 5 . Polycrystalline magnets of Alnico 5 have a maximum energy product of $5 \times 10^{6} \mathrm{G}$ oe and a coercive force of $600 \mathrm{oe}$, while polycrystalline magnets of Alnico 6 have a maximum energy product of $3.65 \times 10^{6} \mathrm{G}$ Oe and a coercive force of 750 oe (5). Alnico 5 is more important commercially because of its higher maximum energy product. In the se alloys, and Alnico alloys in general, the $\alpha_{Y}$ phase is not desirable; therefore, ways to prevent or lessen its formation are important. Commercially, Alnico alloys are cooled very rapidly from their homogenization temperature through the temperature range in which the $\gamma_{1}$ phase is stable. This rapid cooling rate is to preverit the formation of the $\gamma_{1}$ phase and its low temperature product, the $\alpha_{Y}$ phase. Many magnets are too massive to cool rapidly enough to prevent the formation of significant amounts of $Y_{1}$ and $\alpha$.

A referral back to Figure 1 will give an idea of the effect of the $\alpha_{\gamma}$ phase on the properties of Alnico 8 alloys (13). The saturation magnetization (not plotted) remained unchanged over the range of volume per cent of $\alpha_{\gamma}$ studied, indicating that the $\alpha_{\gamma}$ phase has about the same magnetic moment as the $\alpha_{1}+\alpha_{2}$ matrix. An $\alpha_{\gamma}$ phase that is ferro- 
magnetic and isotropic would account for a linear reduction in the residual magnetization by volume dilution of the matrix phase (13), but Julien and Jones found the reduction of the residual magnetization to be nonlinear. This led the authors to suggest that the presence of the $\alpha_{\gamma}$ phase downgrades the properties of the magnet as a whole by somehow affecting the properties of the matrix $\alpha_{1}+\alpha_{2}$ phases.

The purpose of this research project was to study the morphology and crystallography of the $\alpha_{\gamma}$ in Alnico 6 alloys. Although the $\alpha_{\gamma}$ phase was of primary interest, information about other phases was also obtained for comparison. The effect of a magnetic field during the formation of the $\alpha_{y}$ phase was studied also.

The study of Alnico 6, instead of the commercially more important Alnico 5 or Alnico 8, was due to the availability of a large single crystal of this material. With single crystal samples, the interpretation of the data was simplified. 


\section{CHAPTER III}

\section{METHODS AND IECHNIQUES}

\section{SAMPLES STUDIED BY OPTICAL MICROSCOPY AND X-RAY DIFFRACTION}

Throe single crystal samples of Alnico 6 were used for optical microscopy and $X$-ray diffraction work. All three samples were sliced from a large single crystal parallel to the cube faces. The samples were heated in an inert atmosphere of helium for one hour at a temperature of $1250^{\circ} \mathrm{C}$ for homogenization, and water-quenched. One sample was kept in this condition, while another was heated for one hour at $1000^{\circ} \mathrm{C}$, and water-quenched. The remaining sample was heated for one hour at $800^{\circ} \mathrm{C}$, and water-quenched. The three samples were prepared for opt1cal microscope study by mounting them in bakelite, polishing them, and etching them with a solution containing $88 \%$ methanol, $10 \%$ hydrochloric acid, and $2 \%$ liquid bromine, by volume. After optical micrographs were taken of each sample, X-ray diffraction patterns were made using the Lave back-reflection method and a tungsten target operated at $45 \mathrm{kv}$ and $20 \mathrm{ma}$.

\section{SAMPLES STUDIED BY ELECTRON MICROSCOPY AND ELECTRON DIFFRACT ION}

\section{Heat Treatment}

Several single crystal samples of Alnico 6 were placed in two quartz tubes. The tubes were evacuated to a pressure of about $10^{-5} \mathrm{~mm} \mathrm{Hg}$ and sealed. The samples in one tube were heated in a furnace for ons 
hour at a temperature of $1250^{\circ} \mathrm{C}$ for homogenization. The tube of samples was transferred immediately to a magnetic annealing furnace (Figure 2) and kept at a temperature of $1000 \%$ for one hour without a magnetic field. Then the power to the furnace was turned off, and the furnace cooled to $700^{\circ} \mathrm{C}$ in $7 \mathrm{~min}$. The samples were water-quenched from $700^{\circ} \mathrm{C}$ because no appreciable change in structure was expected below this temperature. The second tube of samples was heated for only $37 \mathrm{~min}$ at $1250^{\circ} \mathrm{C}$, and transferred to the magnetic annealing furnace for a $13-\mathrm{min}$ heat treatment at $1000^{\circ} \mathrm{C}$ with a magnetic field of about 5000 oe. ${ }^{*}$ These samples were furnace-cooled to $700^{\circ} \mathrm{C}$ in $7 \mathrm{~min}$ in the presence of the applied magnetic field, and water-quenched. A Varian V-4004 4" electromagnet, with polo pieces tapered to $3^{\prime \prime}$, was used to supply the magnetic field. The field inside the magnetic annealing furnace was measured with a Bell ó20 guassmeter.

The alignment of the samples in the magnetic field was determined by thoir shape. The samples were rectangular parallelepipeds with thickness much less than the width or length. The heat treatment at $1250^{\circ} \mathrm{C}$ caused several samples to stick together because of oxidation, and the faces of the samples were not necessarily parallel. The large faces were observed to be approximately parallel, and the thickness of the combined samples was still less than their width or length. For this reason it was believed that the demagnetizing energy caused the samples to align with their large faces parallel to the direction of the magnetic field. The faces of the samples were parallel to $\{100\}$

*The shorter time at $1250^{\circ} \mathrm{C}$ was necessary to prevent severe oxidation of the samples. The first heat treatment at this temperature resulted in considerable oxidation because the quartz tube devitrified. A short in the heating element caused the shorter time at $1000^{\circ} \mathrm{C}$. 


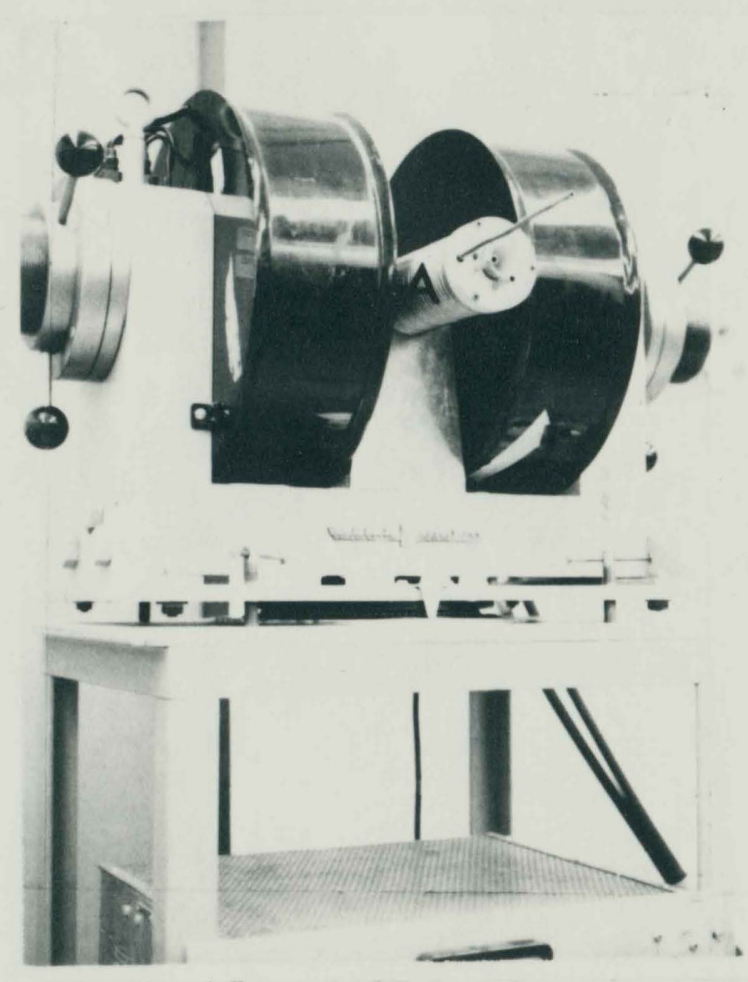

Fiqure 2. Photograph of the magnetic annealing furnace at $A$ positioned between the pole pieces of the $4^{\prime \prime}$ electromagnet. 
planes. The direction of the magnetic field in a $\{100\}$ plane of the different samples was probably dependent on the relative sizes of the samples stuck together and the rotations between the different samples.

\section{Magnetic Annealing Furnace}

Figure 2 shows the magnetic annealing furnace at $A$. The furnace consists of a mullite core, wound with Kanthal wire held on by alundum cement, sitting inside of a copper cylinder. Fiberfrax insulation is between the cement and the inner wall of the copper cylinder.

The mullite core is $18^{\prime \prime}$ long, with $7 / 8^{\prime \prime}$ bore, and $3 / 16^{\prime \prime}$ wall thickness. Grooves of $3 / 32^{\prime \prime}$ width and $3 / 32^{\prime \prime}$ depth provide for 8 turns per inch for the Kanthal wire. The Kanthal wire has diameter of $0.091^{\prime \prime}$ and a resistance of $0.1085 \mathrm{ohm}$ per foot. The ends of the wire are connected in series with variable resistors to an AC source of $220 \mathrm{v}$.

The copper cylinder has a length of $151 / 16^{n}$, an inner diameter of $21 / 8^{\prime \prime}$, and a wall thickness of $1 / 8^{\prime \prime}$. Soldered on each end of the cylinder is a brass flange, $1 / 4^{\prime \prime}$ thick, inner diameter $13 / 4^{\prime \prime}$, and outer diameter $3^{\prime \prime}$. Screwed to each brass flange is a transite plate of $5 / 8^{\prime \prime}$ thickness. One plate has a $11 / 2 "$ hole through which an end of the mullite core protrudes out $9 / 16^{\prime \prime}$ past the plate. The other plate has a $1 / 8^{\prime \prime}$ deep recession of $11 / 2^{\prime \prime}$ diameter in which the other end of the core fits, and a 3/4" diameter hole all the way through it. Soldered around the outer wall of the copper cylinder are 72 turns of copper tubing, having an inner diameter of $0.120^{\prime \prime}$ and an outer diameter of $0.191^{\prime \prime}$. The ends of the copper tubing are connected to rubber hoses, one providing an inlet for cooling. water from a facet, and the other leading to 
a drain.

After the furnace was assembled, it was heated to a temperature of about $1000^{\circ} \mathrm{C}$ for $30 \mathrm{~min}$ to bake the alundum cement. Since both heat treatments, with a magnetic field and without a magnetic field, involved heating the samples for a time period at $1000^{\circ} \mathrm{C}$ and furnace-cooling, it was not necessary to measure the heating rate. With the cooling water running and a current of 16 amp through the heating element, the furnace had three good constant temperature zones near $1000^{\circ} \mathrm{C}$. The length of the zones were about $2^{\prime \prime}$ and the temperature varled about $10^{\circ} \mathrm{C}$ throughout a zone. The temperature distribution was determined by using a ChromelAlumel thermocouple to measure the temperature every $1 \mathrm{~cm}$ along the length of the core.

\section{Electrothinning}

After the heat treatments the samples had to be bombarded with high speed abrasive particles to remove the oxide layers. Then the samples were electropolished to make them thin enough for electron transmission microscopy study. A schematic diagram of the electrothinning circuit is shown in Figure 3. The power source has a $50 \mathrm{v} D C$ output. The voltmeter measures the potential across the electrolytic cell, and the ammeter monitors the current. The recorder provides a record of the variation of the cell voltage with time during the polishing period.

The electrolytic cell is a $50 \mathrm{ml}$ beaker containing about $20 \mathrm{ml}$ of electrolyte. Two platinum wires, one on each side of the sample (anode), serve as the cathode. The electrolyte is a solution containing $80 \%$ thanol and $20 \%$ perchloric acid by volume. 


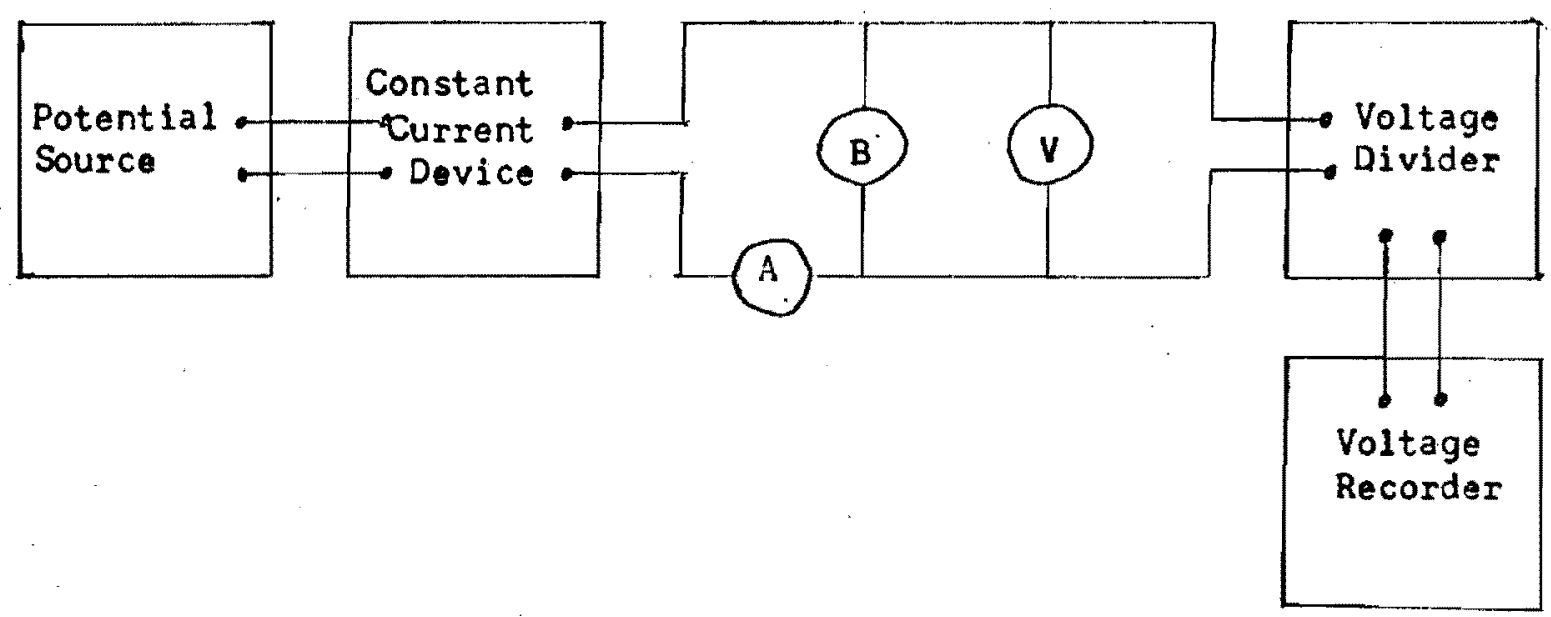

Figure 3. Schematic diagram of the electrothinning circuit with an ammeter at $A$, a voltmeter at $V$, and the electrolytic cell at B. 
The polishing process consists of first lowering the beaker with electrolyte into liquid nitrogen unt 11 the electrolyte begin to freeze. Then the cell is placedbetween the pole pieces of an electromagnet, and the sample placed in the electrolyte with the plane of the sample parallel to the magnetic field. The magnetic field of about 9 koe is used to stir the electrolyte and insure a more uniform polish.

At the beginning of the polishing cycle the potential across the cell is about $50 \mathrm{v}$, and the current through the cell is adjusted to give the current density desired for the particular sample. As the resistance of the electrolyte decreases with its rising temperature, the constant current device maintains the current at its initial value. Samples were polished for periods of about $3 \mathrm{~min}$, and the direction of the magnetic field was reversed every $30 \mathrm{sec}$. At the end of a polishing period, the temperature of the electrolyte was about $-20^{\circ} \mathrm{C}$.

Most of the samples were less than $0.2 \mathrm{~mm}$ thick, and had a surface area of less than $2 \mathrm{~cm}^{2}$. The edges of the samples were insulated with an insulating lacquer prior to electrothinning. The samples were polI shed with a current density between 0.15 and $0.2 \mathrm{amp} / \mathrm{cm}^{2}$. As a sample thinned, holes were observed between the polishing part and the insulated edges. Sometimes holes appeared in the body of the polished part also. These holes grew during further polishing until only small portions of metal was left. At this point it was assumed that at least some of the remaining metal was thin enough for electron transmission microscopy. The polished sample was cut into small pieces and mounted in the spec1men stage of a Hitachi HU-125 electron microscope with an accelerating potential of $125 \mathrm{kv}$. 


\section{CHAPTER IV}

\section{EXPERIMENTAL OBSERVAT IONS}

1. - OPT ICAL MICROSCOPY AND X-RAY DIFFRACTION

The interpretation of the X-ray diffraction patterns was based primarily on a knowledge of the spectrum of a tungsten target operated at $45 \mathrm{kv}$. The continuous spectrum for tungsten at several operating voltages was studied by Ulrey (15). The $K$ lines are not in the spectrum because $45 \mathrm{kv}$ is below the excitation voltages of these lines. The wavelengths and relative intensities of the characteristic $L$ lines are well known (16).

Figure 4 is a dark-field optical micrograph of a single crystal. of Alnico 6 heat treated for one hour at $1250^{\circ} \mathrm{C}$, and water-quenched. The micrograph shows the $\alpha$ phase at a magnification of 590 . An X-ray diffraction pattern of the same sample is shown in Figure 5 . The crystal structure is body-centered cubic, and the orientation is about $6^{\circ}$ from $(001)$

The high intensity of the $(\bar{I} 14)$ and $(1 \bar{l} 4)$ spots in relation to the intensity of the (II4) and (114) spots indicates that the high intensity spots contain some characteristic radiation: Assuming that the (II4) and (1I4) spots contain the L $\beta_{1}$ line gives a lattice parameter of $2.87 \AA$. This conclusion is supported by assuning that the high intensity of the (112) spot is due to a second order reflection containing the $L \gamma_{1}$ line. 


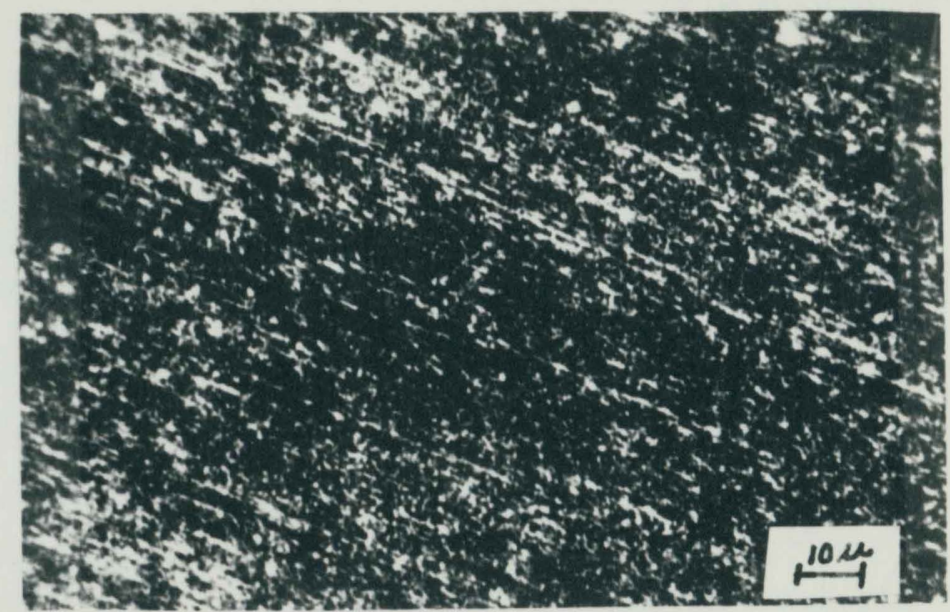

Fiqure 4. Dark field optical micrograph (590X) of the $\alpha$ phase of an Alnico 6 sample heated for $1 \mathrm{hr}$ at $1250^{\circ} \mathrm{C}$ and water-quenched.

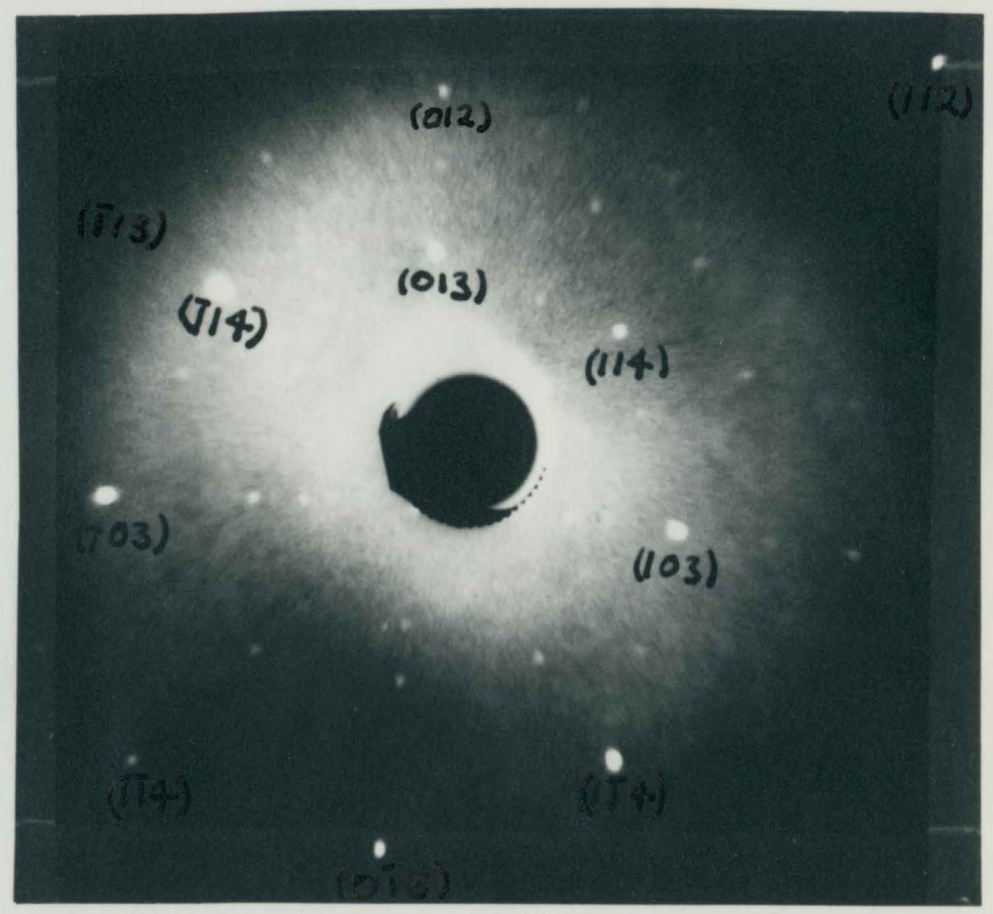

Fiqure 5. X-ray diffraction pattern of the $\alpha$ phase. Orientation is about $6^{\circ}$ from (001). 
The $(\bar{I} 13)$ is a possible ordered spot, but vould require a wavelength of about $1.58 \AA$. Such a wavelength would have a very weak intensity, and whether radiation from first order diffraction is contained in the spot can not be determined. Most of the radiation is from third and fourth order reflections. The same kind of reasoning applies to the other $\{311\}$ spots, and to the (012) spot. The question of ordering is left unanswered by using white radiation for diffraction work.

The high, but relatively even, intensity of the $\{310\}$ spots can be attributed to several wavelengths in the high intensity region of the tungsten continuous spectrum giving rise to diffraction of different. orders. Using the lattice parameter, wavelengths contributing to third, fourth, and fifth order diffraction are in the high intensity portion of the continuous spectrum.

Figures 6 and 7 are an optical micrograph and an $X$-ray diffraction pattern of the sample heated for one hour at $1000^{\circ} \mathrm{C}$ and water-quenched. The micrograph shows the microstructure of the $\propto$ phase (13ght area) and the $\alpha_{\gamma}$ phase (dark area) at a magnification of 590 .

The interpretation of the $X$-ray pattern is essentially the same as that for the sample heated at $1250^{\circ} \mathrm{C}$. The crystal structure is bodycentered cubic, and information about ordering is not dependable for reasons given before. The orientation is about $2^{\circ}$ from $(001)$. The intensity distribution of the $\{510\}$ spots indicates that the $(015)$ and (i05) spots contain characteristic radiation. Considering that these spots contain the $L \gamma_{1}$ line leads to a lattice parameter of $2.87 \AA$. This is supported by the high intensity of the $\{411\}$ spots wich is believed to be due to one or mare of the L $\beta$ lines. 


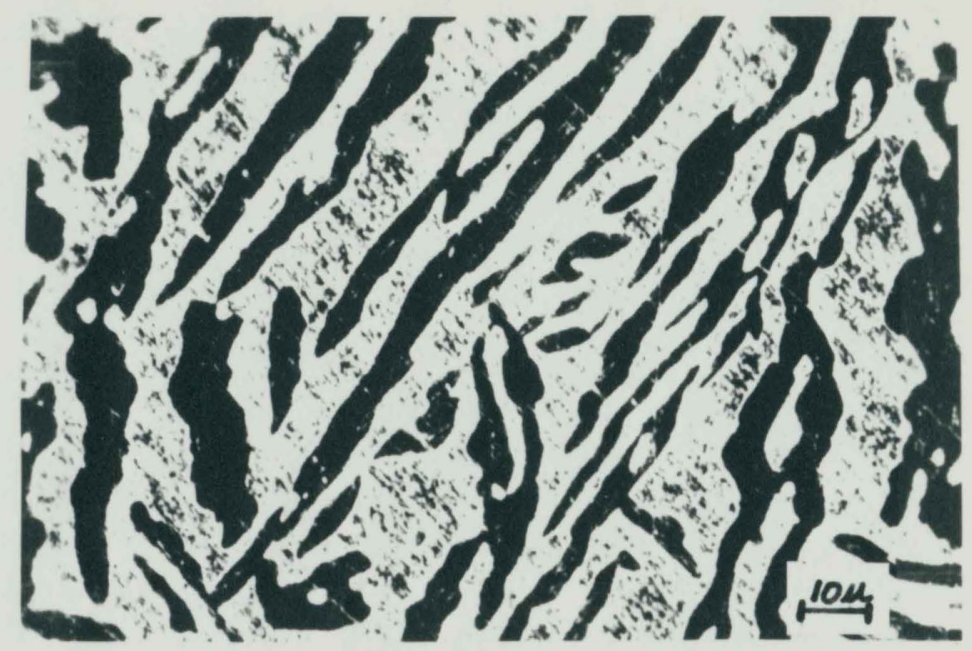

Figure 6. Dark field optical micrograph (590X) of the $\alpha$ and $\alpha_{\gamma}$ phases of a sample of Alnico 6 heated for $1 \mathrm{hr}$ at $1000^{\circ} \mathrm{C}$ and waterquenched.

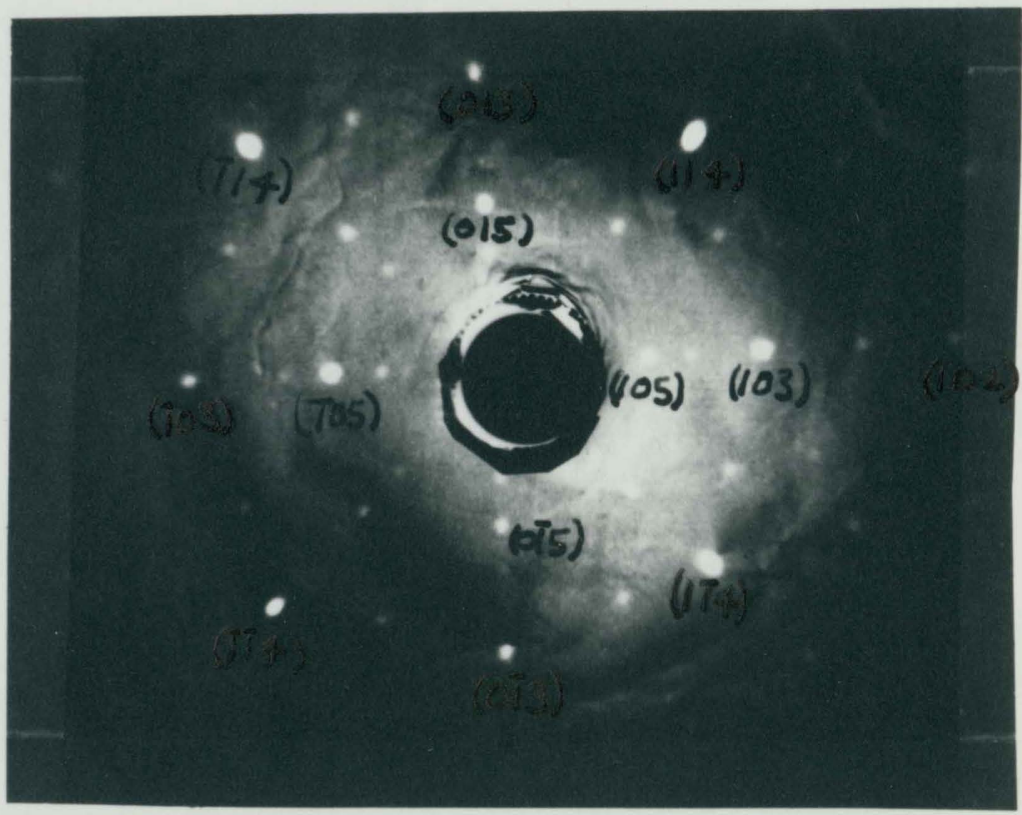

Figure 7. $\quad X$-ray diffraction pattern of the $\alpha$ and $\alpha_{\gamma}$ phases. Orientation is about $2^{\circ}$ from $(001)$. 
This is a diffraction pattern of two phases, $\alpha$ and $\alpha_{Y}$. As to which phase the lattice parameter belongs is left in question. The phases seem to be aligned such that crystallographic directions in the two phases are parallel. Selected area electron diffraction was used to clarify these questions concerning lattice parameter, ordering, and orientation relationship. This material will be presented later.

Shown in Figuros 8 and 9 are an optical micrograph and $X-r a y$ diffraction pattern of the single crystal of Alnico 6 heated for one hour at $800^{\circ} \mathrm{C}$, and water-quenched, after a heat treatment at $1250^{\circ} \mathrm{C}$ for homogenization. The micrograph shows the $\alpha_{1}+\alpha_{2}$ phases. No clear phase separation is noted because the individual particles are too small to be resolved with the optical microscope.

The X-ray diffraction pattern is essentially one of a single phase. The crystal structure is body-centered cubic. The orientation is about $2^{\circ}$ from $(001)$ as in the case of the sample heated at $1000^{\circ} \mathrm{C}$. As with that sample, the intensity of the (I05) and (015) spots indicates characteristic radiation, leading to a lattice parameter of $2.87 \AA$. A (102) spot was on the negative, but this does not definitely indicate ordering since white radiation was used.

Two samples were electropolished prior to heat treatment. One sample was placed in the quartz tube with the samples heat treated without a magnetic field, and the other sample was placed in the tube with the samples hoat treated with a magnetic field. The plan was to observe these samples after heat treatment using the optical microscope to see if surface rellef effects were present. Qurface relief effects were expected if the $\gamma_{1} \rightarrow \alpha_{\gamma}$ transformation occurred martensitically 


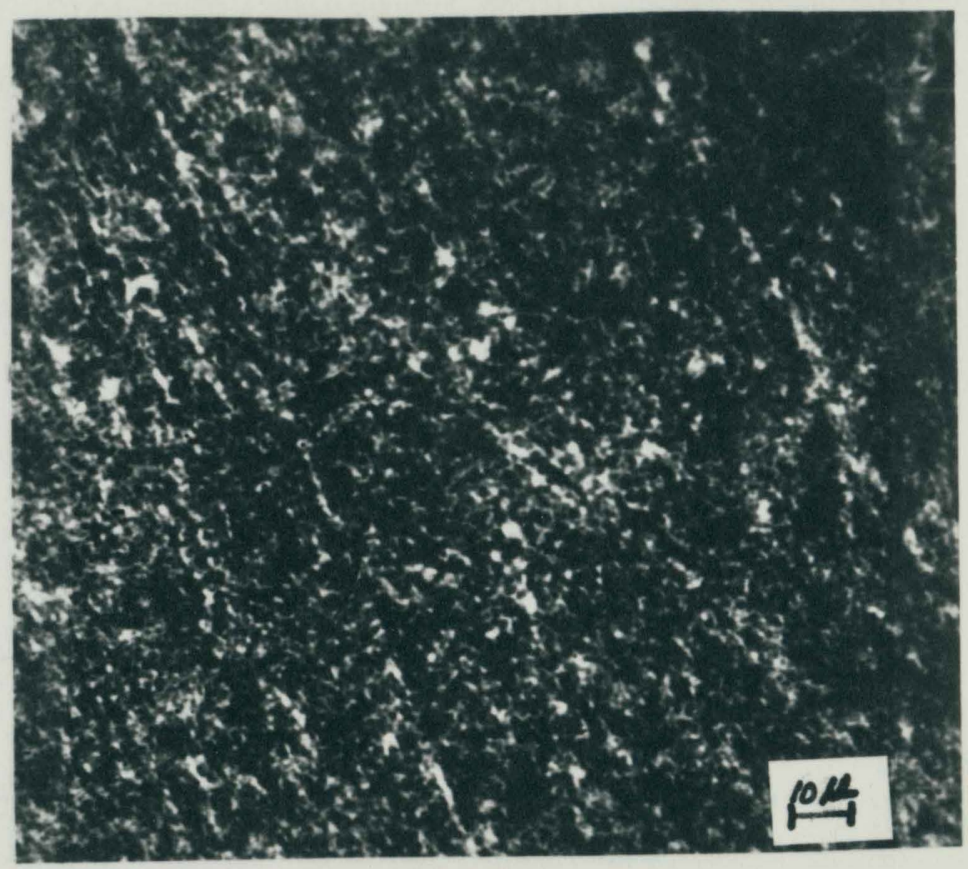

Figure 8. Dark field optical micrograph of the $\alpha_{1}$ and $\alpha_{2}$ phases of an Alnico 6 sample heated for $1 \mathrm{hr}$ at $800^{\circ} \mathrm{C}$ and wáter-quenched. (590X)

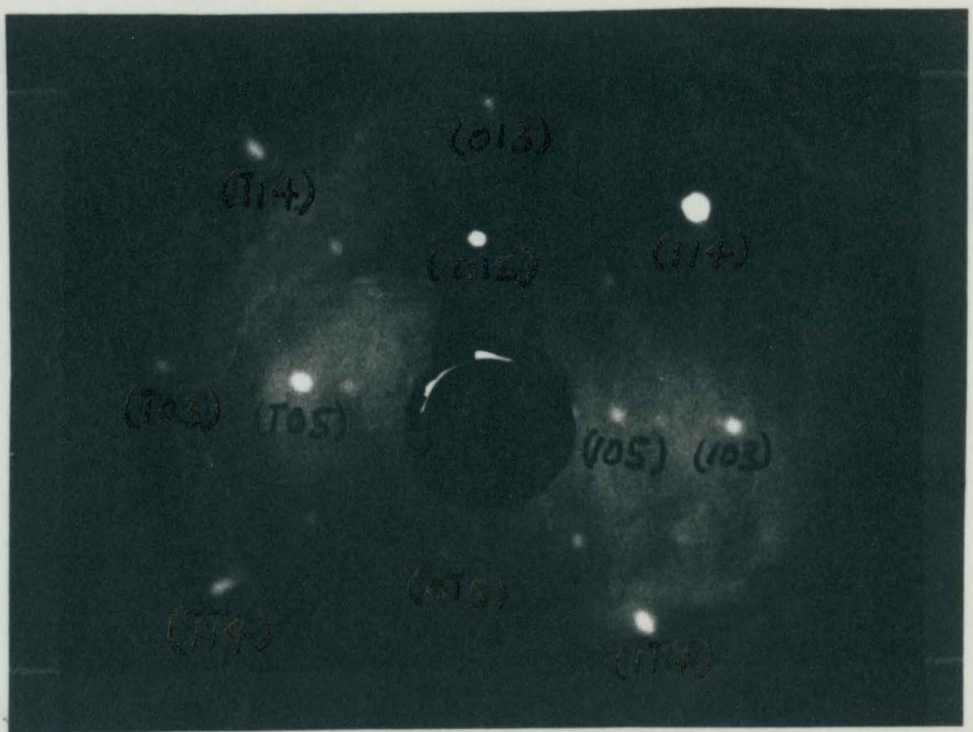

Figure 9. X-ray diffraction pattern of the $\alpha_{1}$ and $\alpha_{2}$ phases. Orientation is about $2^{\circ}$ from $(001)$. 
(without diffusion in the usual sense of the word, but with well-defined movement of the atoms in going from one phase to the other). Unfortunately the quartz tubes devitrified, and the samples became oxidized, and had to be polished and etched. Whether or not surface relief offects were present as a result of a martensitic transformation was undetermined. Figure 10 is an optical micrograph of the sample heat treated without a magnetic field. Figure 11 is a micrograph of the sample heat treated with a magnetic field. The micrographs show the $\alpha_{\gamma}$ phase as the elongated particles in the $\alpha_{1}+\alpha_{2}$ matrix. The relief effects are due to the polishing and etching process as a consequence of the difference in hardness and composition of the phases.

\section{ELECTRON MICROSCOPY AND ELECTRON DIFFRACTION}

\section{Samples Heat Ireated without a Magnet ic Field}

Thin samples of Alnico 6 heat treated without a magnetic field were observed in the electron microscope with an accelerating voltage of $125 \mathrm{kv}$. Both $\alpha_{\gamma}$ regions and $\alpha_{1}+\alpha_{2}$ regions were observed in each sample.

Figure 12 is an electron micrograph showing the $\alpha_{\gamma}$ and $\alpha_{1}+\alpha_{2}$ phases. The difference in morphology is readily apparent. The $\alpha_{X}$ phase is the area protruding down to the left, while the $\alpha_{1}+\alpha_{2}$ phases protxude down to the right. The $\alpha_{Y}$ phase seems to have some kind of structures elongated along the [001] direction. The $\alpha_{1}+\alpha_{2}$ phases have $a$ thin region on the left edge and a thicker region to the right. In the thin region the light particles are believed to the ferromagnetic Fe-Co rich $\alpha_{2}$ phase, while the gray matrix is believed 


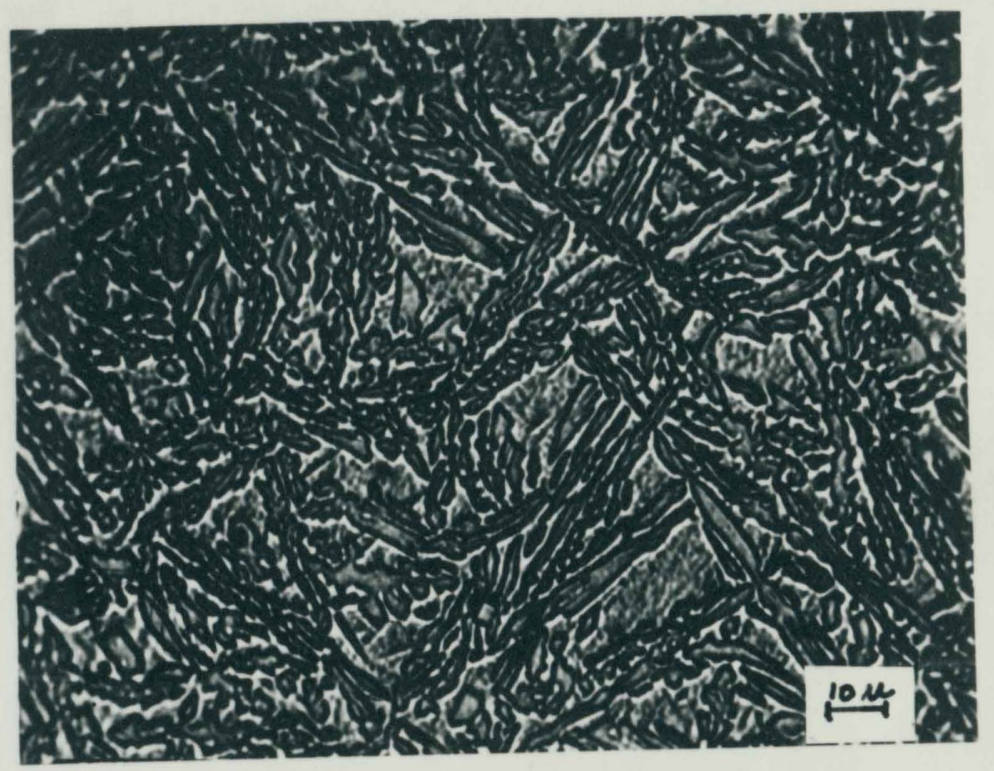

Fiqure 10. Bright field optical micrograph (590X) of a sample of Alnico 6 heat treated without a magnetic field and furnace-cooled.

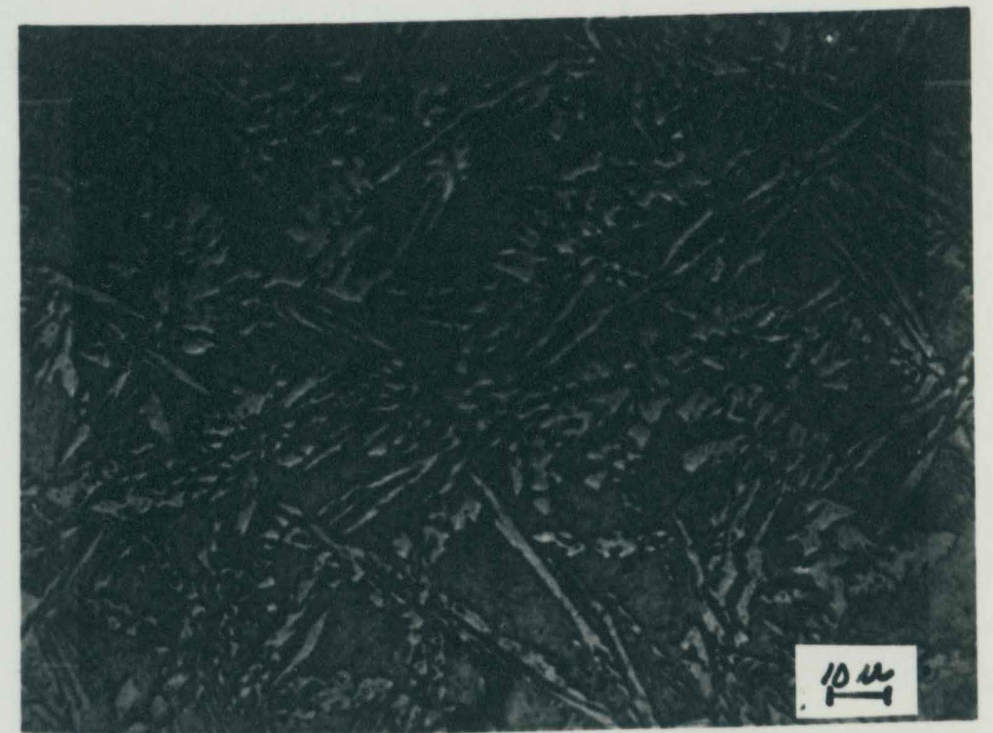

Figure 11. Bright field optical micrograph (590X) of a sample of Alnico 6 heat treated with a magnetic field and furnace-cooled. 


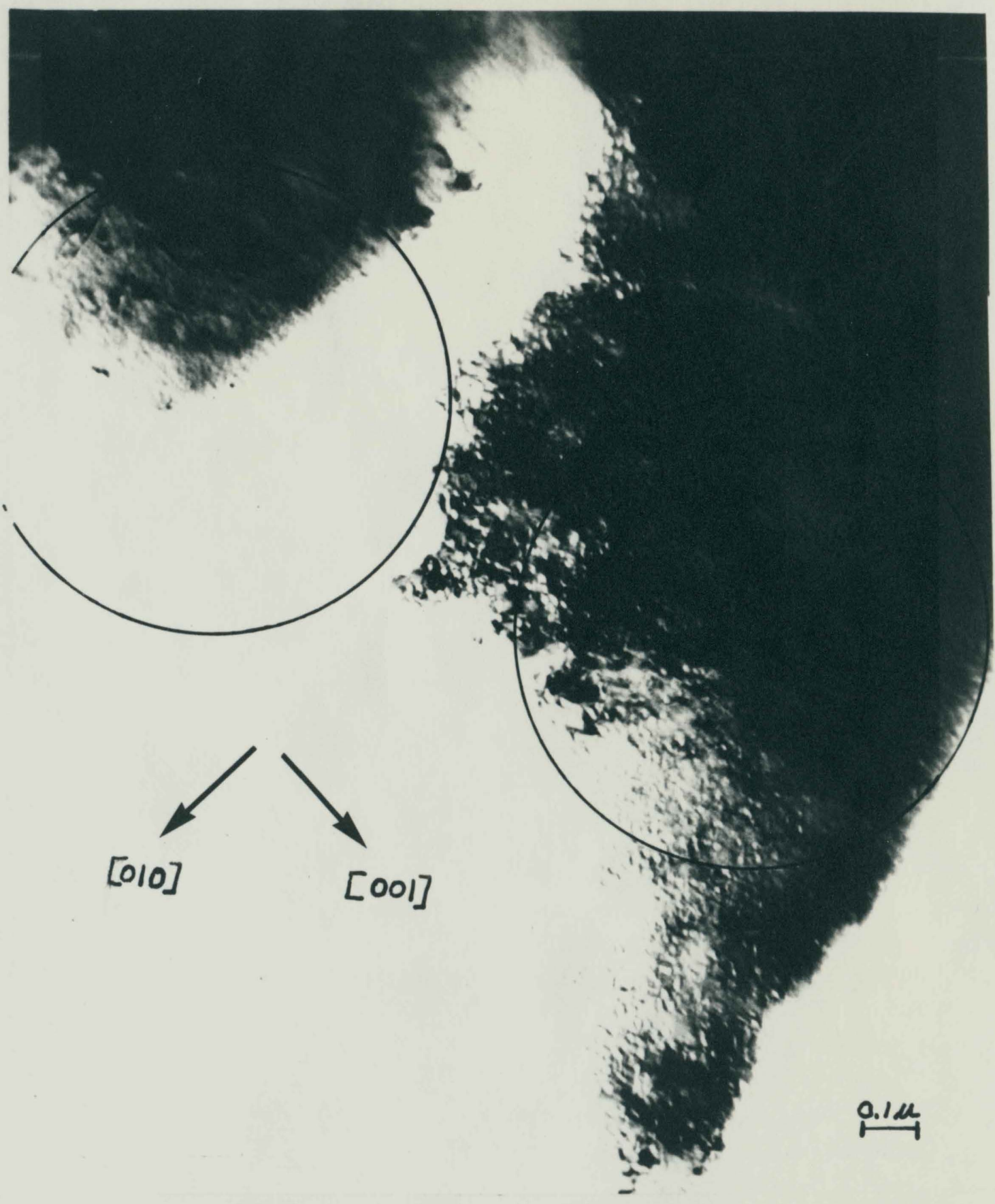

Figure 12. Electron micrograph $(79,000 \mathrm{X})$ showing the $\alpha_{\boldsymbol{\gamma}}$ phase (left) and the $\alpha_{1}+\alpha_{2}$ phases (right) of a sample heat treated without a magnetic field and furnac-cooled. 
to be the weakly ferromagnetic, Ni-Al rich $\alpha$, phase. In the thick region the gray particles are believed to be the $\alpha_{2}$ phase, and the darker matrix is believed to be the $\alpha_{1}$ phase. The thick region shows that the $\alpha_{2}$ particles are generally elongated along the [001] direction. The fact that no particles seem to be elongated along the [010] direction may be due to the orientation of the sample; therefore, what is observed is a projection of the particles onto the plane normal to the electron beam (17). Rapid cooling did not allow the $\alpha_{1}+\alpha_{2}$ structure to develop. Figure 13 is an electon diffraction pattern of the $\alpha_{1}+\alpha_{2}$ phases taken from the encircled area on the right in Figure 12. The orientation is very near (100), but the high intensity of the (020) spot in relation to the other $\{020\}$ spots indicates that the orientation is not exactly $(100)$. The diffraction pattern shows a high degree of ordering in a body-centered cubic structure with a lattice parameter of about $2.87 \AA$. The ordered spots are from the $\alpha$, phase (18). The cause of the diffuse streaks normal to the $\langle 110\rangle$ directions is uncertain, although previous investigators (19) have suggested that these are due to fine particles of the face-centered cubic phase $\left(\gamma_{2}\right)$ precipitated in the $\alpha_{1}+\alpha_{2}$ matrix. The reason for the splitting of the $\{310\}$ spots at $B$ and $C$ is unknown.

Figure 14 is an electron diffraction pattern of the $\alpha_{\gamma}$ phase taken from the area encircled on the left in Figure 12. The orientation is the same as that for the $\alpha_{1}+\alpha_{2}$ phases, and the crystal structure is the same. The electron diffraction patterns of the $\alpha_{y}$ phase and the combined $\alpha_{1}+\alpha_{2}$ phases were compared, but no difference in lattice parameters was detected. Any difference in lattice parameters was expected to be quite small and beyond the accuracy of lattice spacing 


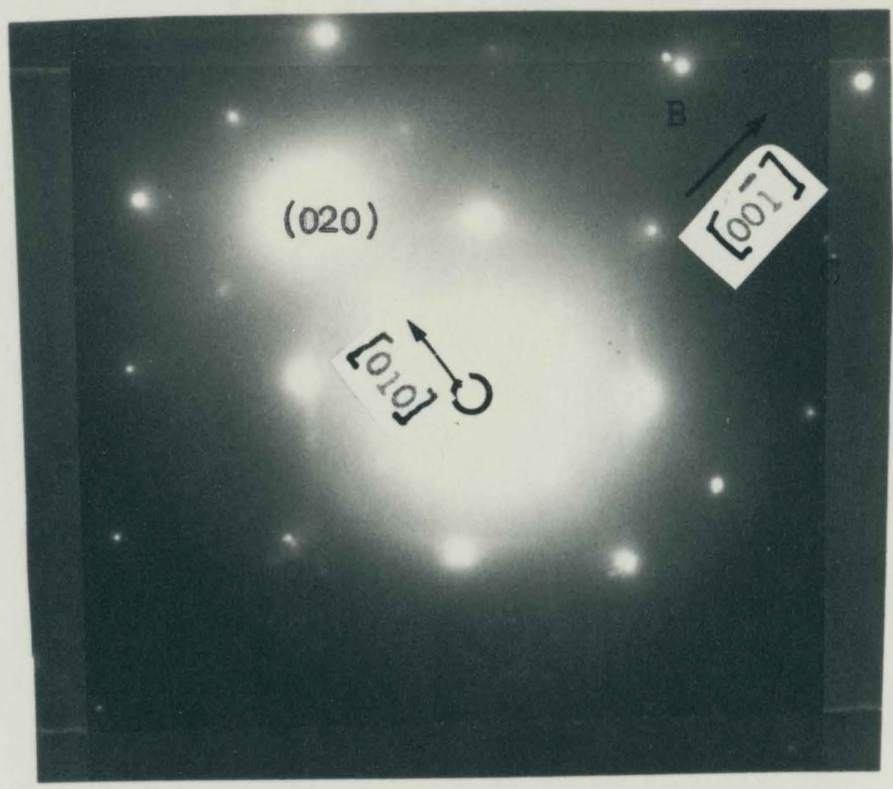

Fiqure 13. Electron diffraction pattern of the $\alpha_{1}+\alpha_{2}$ phases. Orientation is near (100).

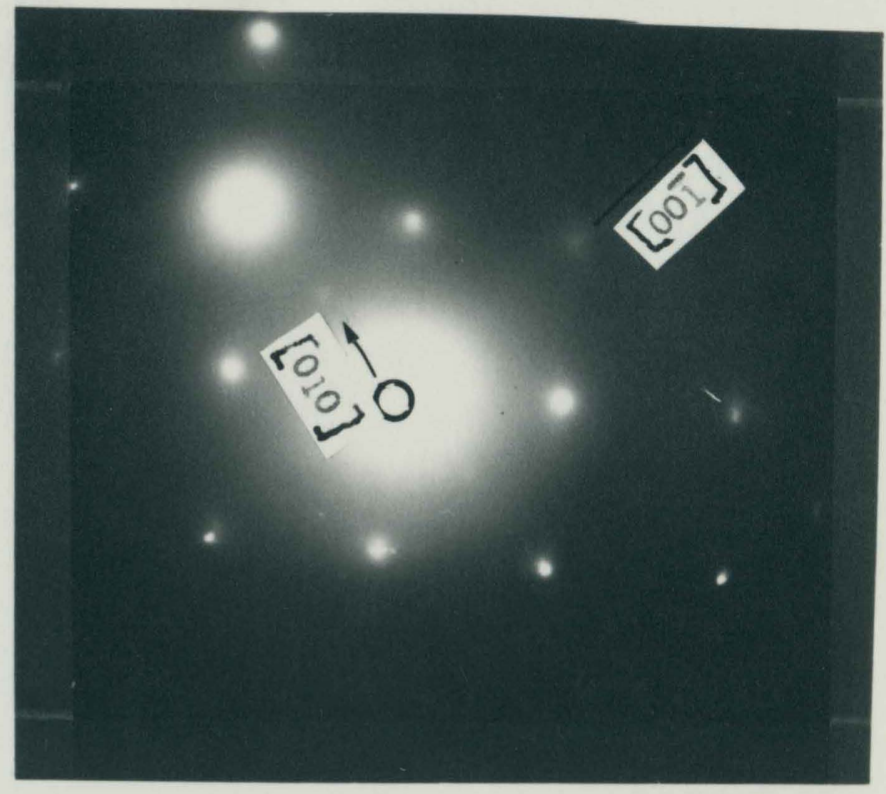

Fiqure 14. Electron diffraction pattern of the $\alpha_{\gamma}$ phase. Orientation is near (100). 
determinations using electron diffraction.

The morphology of the $\alpha_{\gamma}$ and $\alpha_{1}+\alpha_{2}$ phases of another sample of Alnico 6 is shown in Figure 15. The area enclosed in the rib-like boundary is the $\alpha_{\gamma}$ phase. The $\alpha_{1}+\alpha_{2}$ phases are in the region in the right of the photograph. The dark portion of the resolved region of the $\alpha_{1}+\alpha_{2}$ phases is believed to be the $\alpha_{1}$ phase, while the light portion is believed to be the $\alpha_{2}$ phase. A separation of about $200 \dot{A}$ is obsorved between the $\alpha_{2}$ particles, which is about what is expected from theory. The boundary between the $\alpha_{\gamma}$ phase and $\alpha_{1}+\alpha_{2}$ phases is of the order of $1000 \AA$ thick, and is made up of particles of the face-centered cubic phase $\left(\gamma_{1}\right)$ that appear as the light areas in the boundary (19). The long straight portion of the boundary is along the [001] direction.

Figure 16 is an electron diffraction pattern of the $\alpha_{1}+\alpha_{2}$ phases taken from the area encircled on the right in Figure 15. Figure 17 is a diffraction pattern of the $\alpha_{\gamma}$ phase taken from the area encircled on the left in Figure 15. The orientation is near (100) for both diffraction patterns. The conclusions about crystal structure and ordering are the same as those reached for the other sample heat treated without a magnetic field. Figures 16 and 17 both have an ordered spot indicated by $A$. The degree of ordering is higher in the $\alpha$, phase than in the $\alpha_{\gamma}$ phase.

Samples Heat Ireated with a Magnetic Fielc

Several single crystal samples of Alnico 6, heat treated in a magnetic field of about 5000 oe, were observed in the electron microscope. The accelerating voltage was $125 \mathrm{kv}$. 


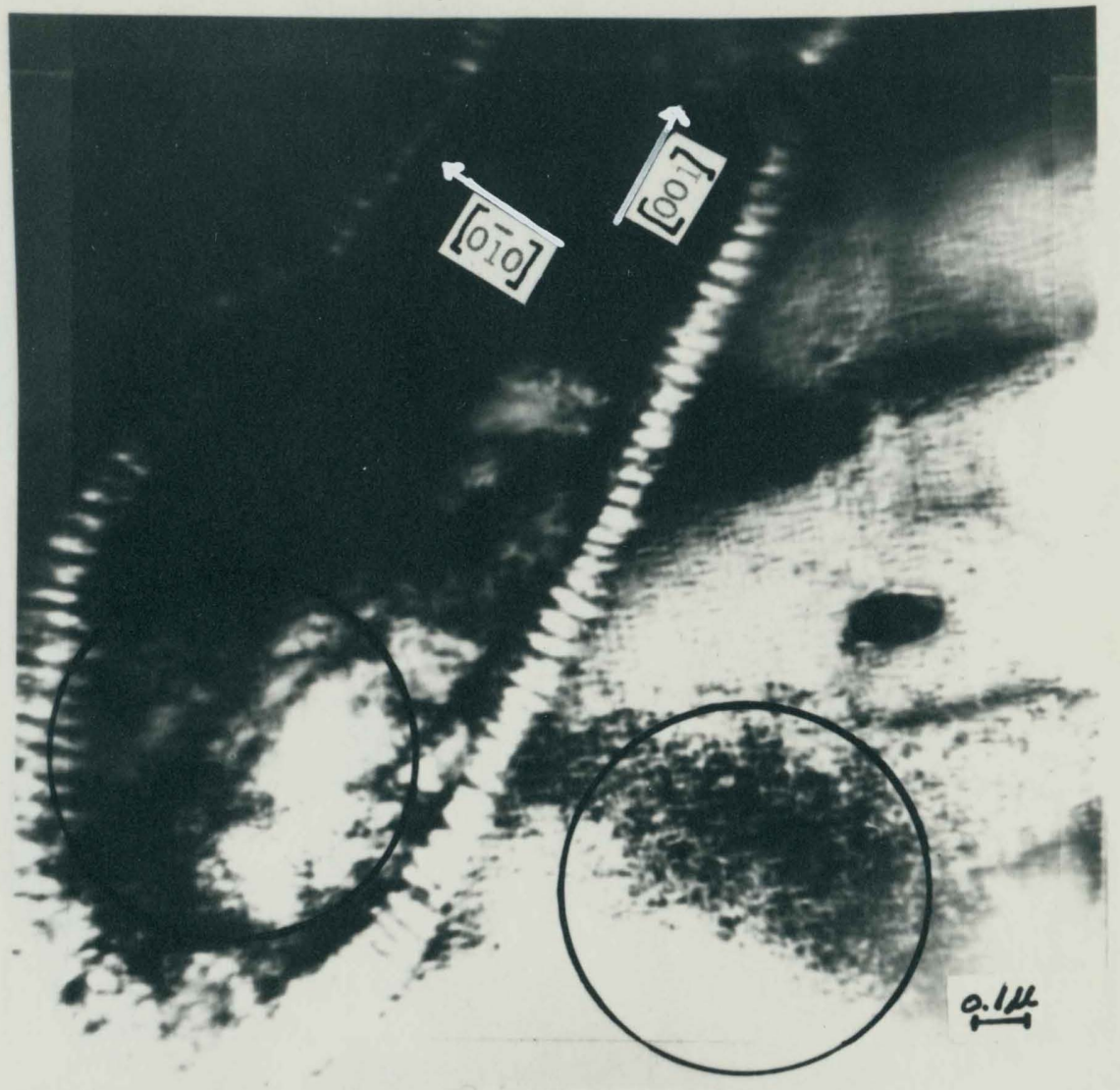

Fiqure 15. Electron micrograph $(56,400 \mathrm{X})$ showing the (100) plane of an Alnico 6 sample heat treated without a magnetic field and furnace-cooled. 


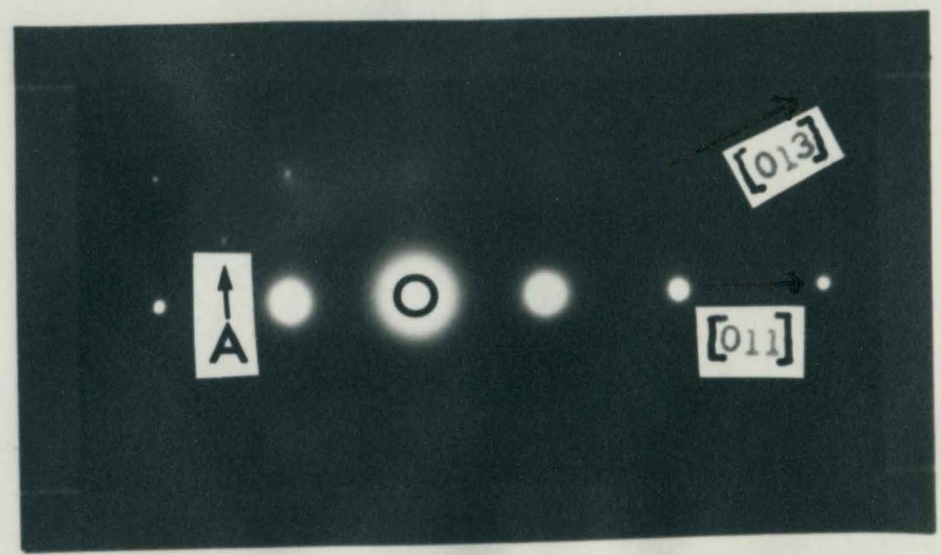

Fiqure 16. Electron diffraction pattern of the $\alpha_{1}+\alpha_{2}$ phases. Orientation is near (100).

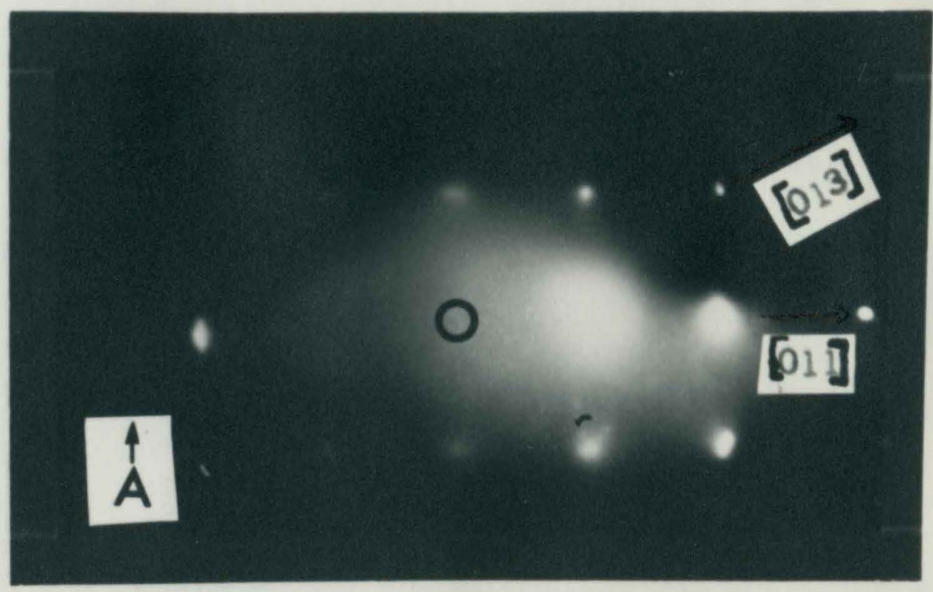

Fiqure 17. Electron diffraction pattern of the $\alpha$ phase. Orientation is near (100). (The ordered spot indicated by $\mathrm{A}$ does not show on this print.) 
Figure 18 is an electron micrograph showing the $\alpha_{1}+\alpha_{2}$ phases (with $A$ above) and the $\alpha_{\gamma}$ phase (with $B$ above). The light, linear area between the $\alpha_{1}+\alpha_{2}$ phases and the $\alpha_{\gamma}$ phase is the $\gamma_{1}$ phase. An electron diffraction pattern of the $\alpha_{1}+\alpha_{2}$ phases is shown in Figure 19, with the upper circle in Figure 18 indicating the area the pattern was taken from. The orientation is near $(11,3,1)$. Figure 20 is and electron diffraction pattern of the $\alpha_{\gamma}$ phase taken from the lower encircled area in Figure 18. The orientation of the matrix is again $(11,3,1)$, but some twin spots are present. Spots at $A$ and $B$ are believed to be $\{440\}$ and $\{431\}$ twin spots, respectively.

An electron micrograph of the $(100)$ plane of the $\alpha_{\gamma}$ phase and the $\alpha_{1}+\alpha_{2}$ phases is shown in Figure 21. The area indicated by $A$ is the $\alpha_{1}+\alpha_{2}$ region, while the area indicated by $B$ is the $\alpha_{\gamma}$ region. Traces of the $\gamma_{1}$ phase can be seen between the $\alpha_{1}+\alpha_{2}$ phases and the $\alpha_{\gamma}$ phase. The lighter particles in the $\alpha_{1}+\alpha_{2}$ region are the $\alpha_{2}$ phase. The particles are elongated along a direction making an angle of about $15^{\circ}$ with the $[010]$ direction. The darker matrix is the $\alpha$, phase. Figure 22 is an electron diffraction pattern of the $\alpha_{1}+\alpha_{2}$ phases taken from the area encircled on the right in Figure 21. Figure 23 is an electron diffraction pattern of the $\alpha_{\gamma}$ phase taken from the encircled on the left in Figure 21. Although the orientation in both patterns is near the (100) plane, the intensity distribution on the patterns indicates a slight orientation difference between the $\alpha_{1}+\alpha_{2}$ phases and the $\alpha_{\gamma}$ phase. The electron micrograph indicates that the $\alpha_{\gamma}$ phase is thinner than the $\alpha_{1}+\alpha_{2}$ phase, and this would account for a slight orientation difference if the surfaces of the two regions 


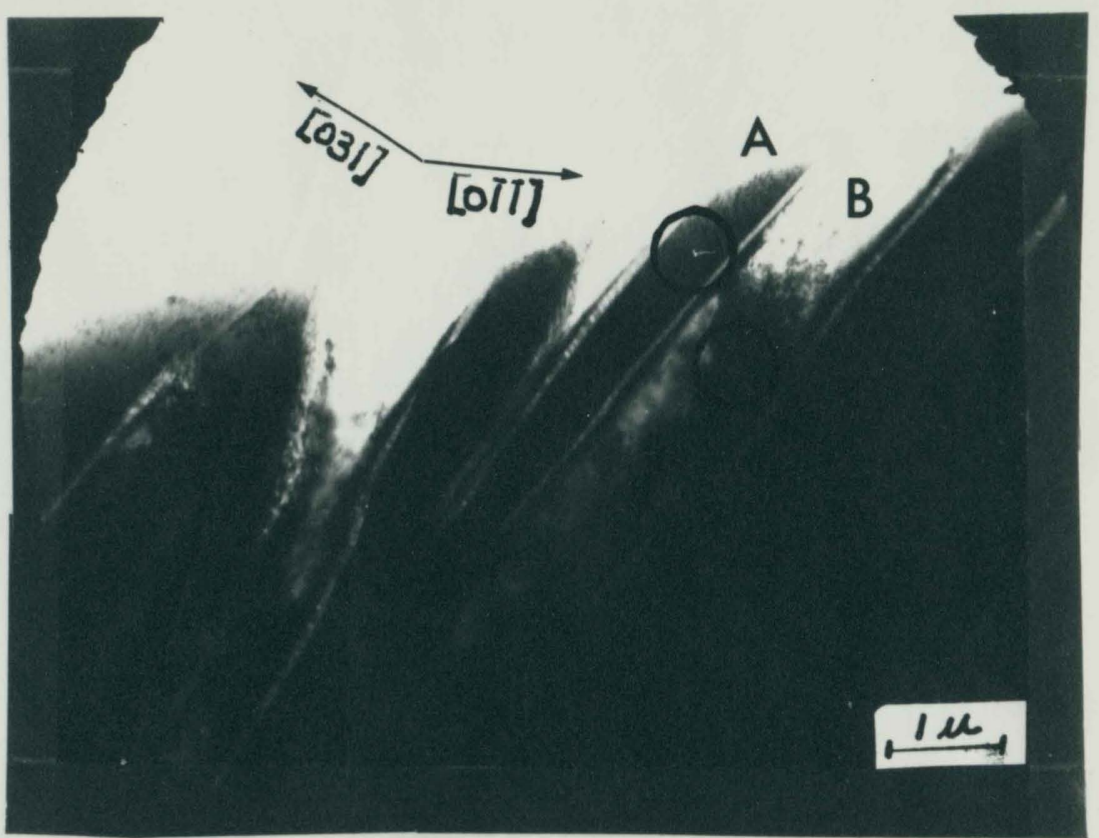

Figure 18. Electron micrograph $(11,800 \mathrm{X})$ of an Alnico 6 sample heat treated with a magnetic field and furnace-cooled. 


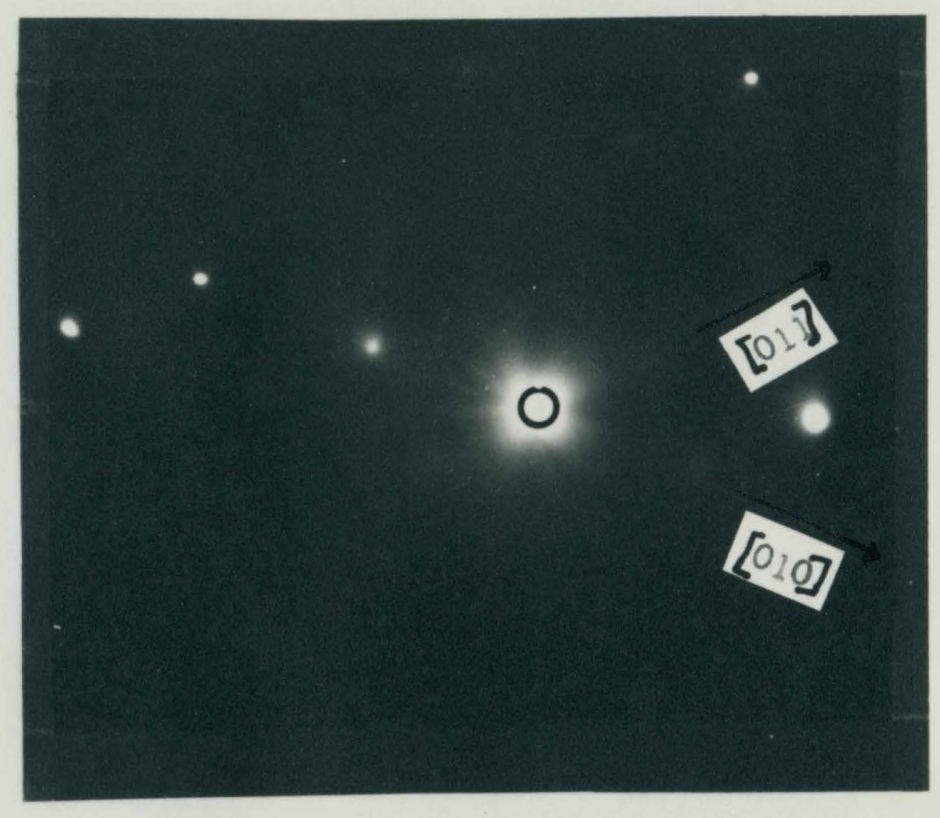

Fiqure 19. Electron diffraction pattern of the $\alpha_{1}+\alpha_{2}$ phases. Orientation is near $(11,3,1)$.

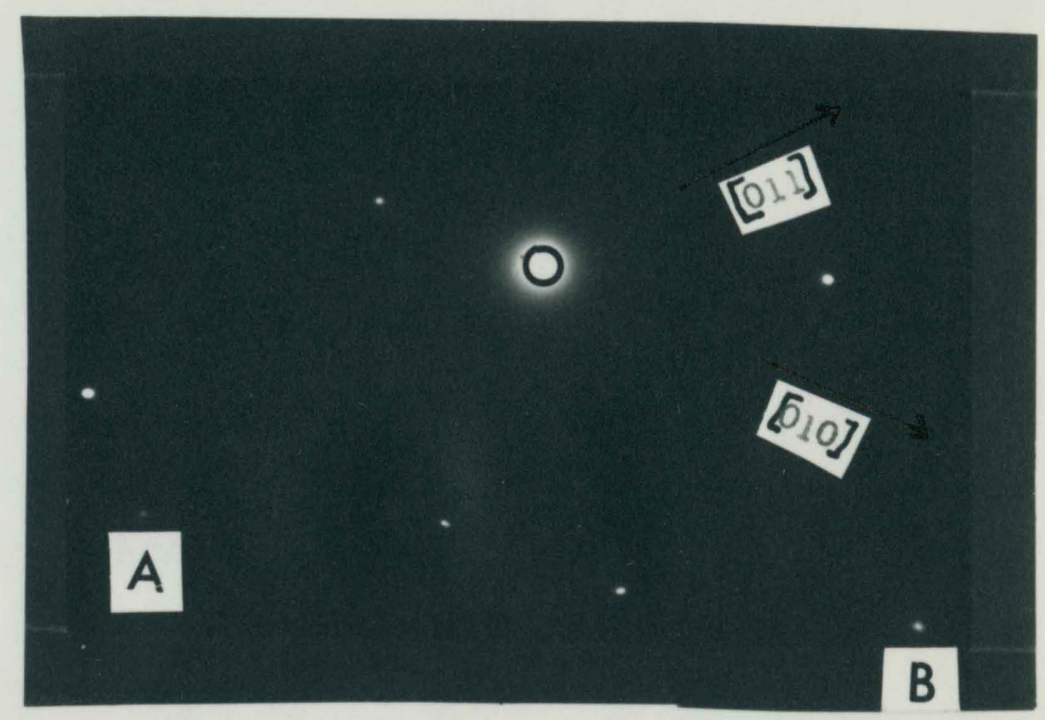

Fiqure 20. Electron diffraction pattern of the $\alpha_{\gamma}$ phase. Orientation of the matrix is near $(11,3,1)$. 


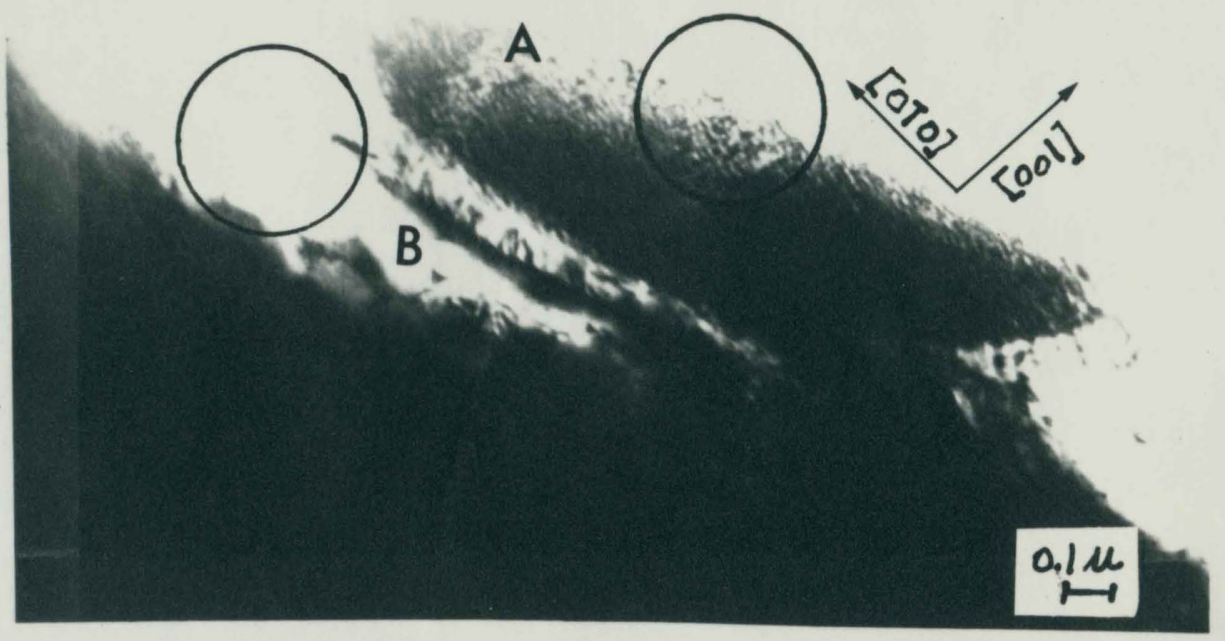

Fiqure 21. Electron micrograph $(45,000 \mathrm{X})$ of an Alnico 6 sample heat treated with a magnetic field and furnace-cooled.

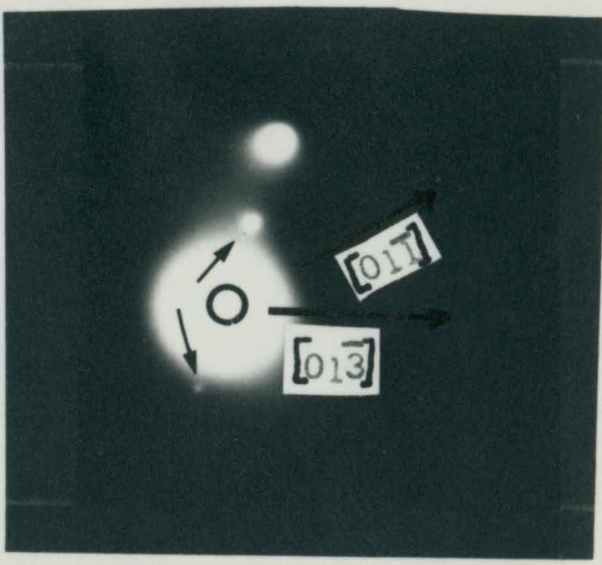

Fiqure 22. Electron diffraction pattern of the $\alpha_{1}+\alpha_{2}$ phases. Orientation is near (100).

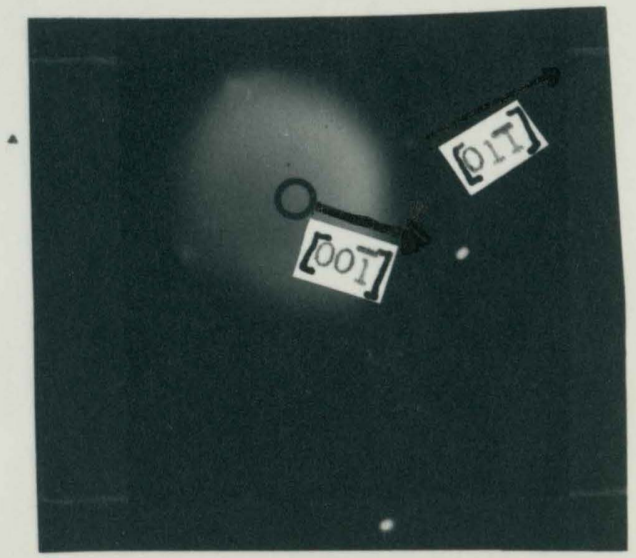

Fiqure 23. Electron diffraction pattern of the $\alpha_{\gamma}$ phase. Orientation is near (100). 
were not parallel. Another significant difference between the two diffraction patterns is the ordered $\{010\}$ spots for the $\alpha_{1}+\alpha_{2}$ phases (Indicated by the two small arrows), and no observed ordered spots for the: $\alpha_{Y}$ phase. The unordered spots in the $\alpha_{\gamma}$ diffraction pattern are not very intense, and if there are ordered spots they may be obscured by the intensity of the undeviated electron beam.

Shown in Figure 24 is an electron micrograph of a relatively large $\alpha_{\gamma}$ region. The dark portions are thought to be areas of high dislocation density.

Figure 25 is an electron diffraction pattern of the area encircled in Figure 24. The orientation of the matrix is near (11i), and there is another $\{111\}$ plane (rotated $10^{\circ}$ counterclockwise with respect to the matrix) and a $\{931\}$ plane on the photograph.

The area that the diffraction pattern was taken from shows traces of what are thought to be either slip planes or twinning planes. The trace in the upper portion of the circle is made up of two segments with a small rotation between the segments on crossing a darker area of dislocations. The lower trace is made up primarily of three segments--two short segments to the right, and a longer segment to the left. Note that the segments for both traces are essentially parallel, except for about a $10^{\circ}$ rotation counterclockwise of the left segment of the lower trace from the other segments.

All of the segments of the traces are nearly parallel to the [110] direction of the matrix, indicating that they could be traces of the (112) plane or the (112) plane. These planes are possible slip planes or twinning planes for a body-centered cubic structure. Spots $A$ and $B$ on 


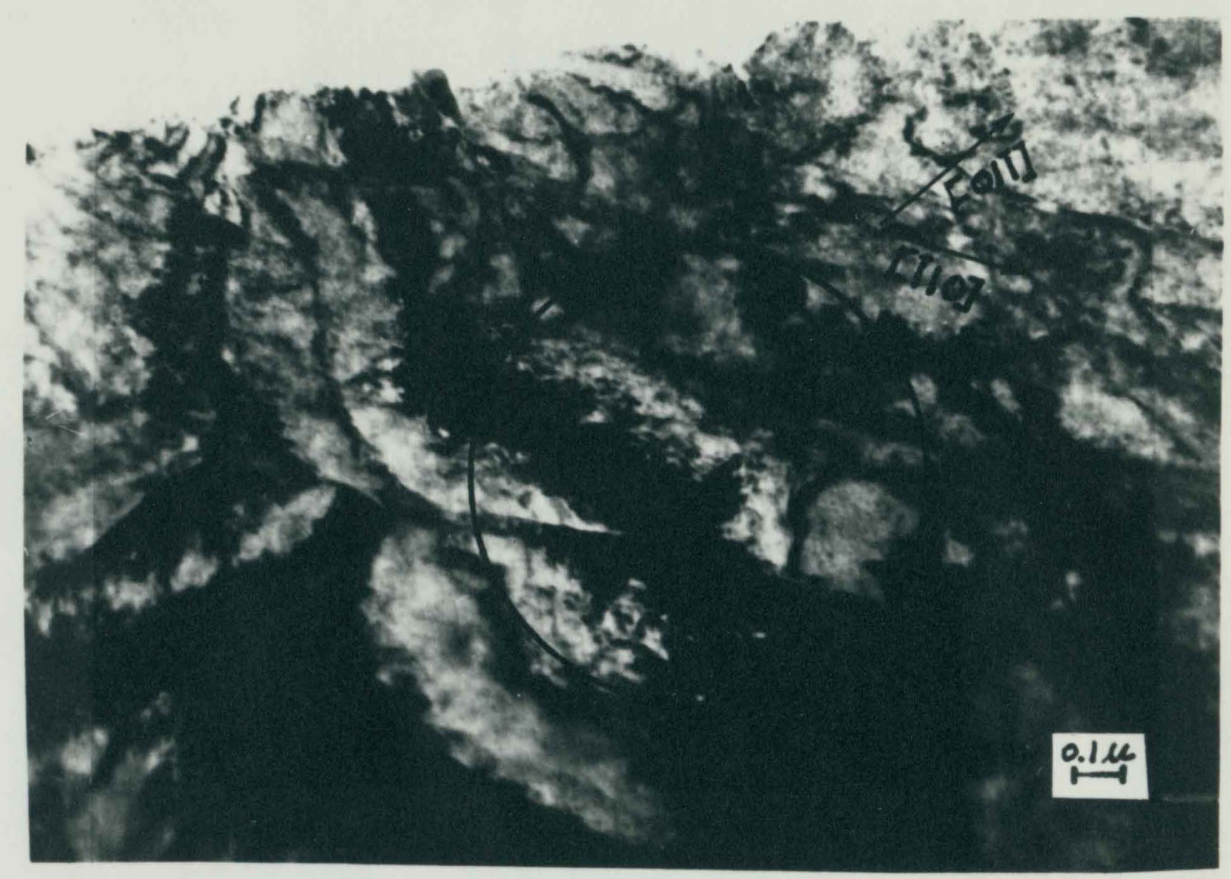

Figure 24. Electron micrograph $(45,000 \mathrm{x})$ of the $\alpha_{\boldsymbol{\gamma}}$ phase showing a high density of dislocations and traces of a twinning plane.

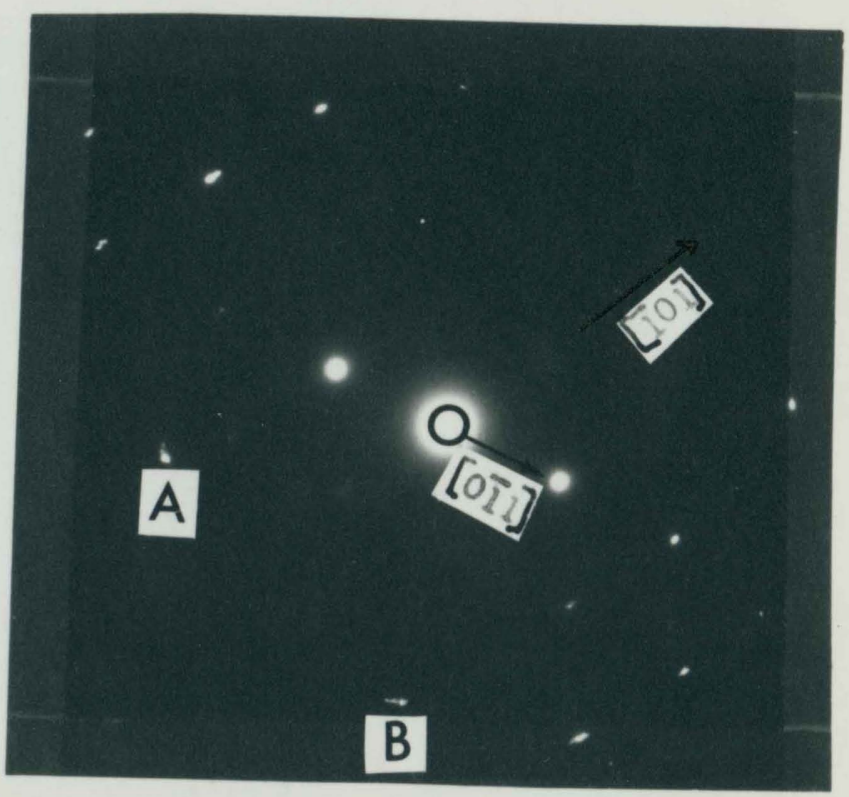
Fiqure 25
tation of the matrix is near $(111)$. 
the diffraction pattern are $\{310\}$ spots, and can be indexed on the (319) plane. The (319) plane is less than $9^{\circ}$ from the (115) plano, which would be parallel to the (111) plane due to twinning on the (112) plane. For this reason, the conclusion is that the traces represent the (112) twinning planes. The second (111) plane of the pattern is thought to be due to a $10^{\circ}$ lattice rotation across the large dark area of dislocations. The splitting or broadening of some of the spots is thought to be due to smaller lattice rotations across smaller areas of dislocations.

The twinning in the $\alpha_{\gamma}$ phase of the samples heat treated in a. magnetic field is puzzling, since no twinning was found in the $\alpha_{\gamma}$ phase of the samples heat treated without a magnetic field. $X$-ray diffraction of two samples, one heat treated with a magnetic field and the other heat treated without a magnetic field, indicated that this is a general result. Iwinning in the $\alpha_{\gamma}$ phase is expected if the $\gamma_{1} \rightarrow \alpha_{\gamma}$ transformation occurs martensitically. (20), and the magnetic field is expected to raise the transformation temperature a few degrees (21). Whether or not the $\gamma_{1} \rightarrow \alpha_{\gamma}$ triansformation in Alnico 6 ocrurs martensitically is not known, and the reason for twinning in one case and not in the other case is left in question.

Figure 26 is an electron micrograph of the $\alpha_{1}+\alpha_{2}$ phases and three lens-shaped particles of unknown structure. Figure $27 \mathrm{a}$ is an electron diffraction pattern of the area enclosed in the lower circle in Figure 20. The orientation of the $\alpha_{1}+\alpha_{2}$ phases is near (311). The arrow on the left of the pattern indicates a $\{620\}$ spot, and the arrow on the right indicates a $\{440\}$ spot. These spots are on a $\{100\}$ plane 
of the $\gamma_{2}$ phase. The $\gamma_{1}$ phase is indicated by A in Figure 26. Figure $27 \mathrm{~b}$ is an electron diffraction pattern of the $\alpha_{1}+\alpha_{2}$ phases and one of the lenticular particles taken from the area in the upper circle in Figure 26. The spot indicated by the arrow is from the lenticular particle. (What appears to be one spot on the print is actually two spots, and the one closest to the center of the pattern is from the lens-shaped particle.) 


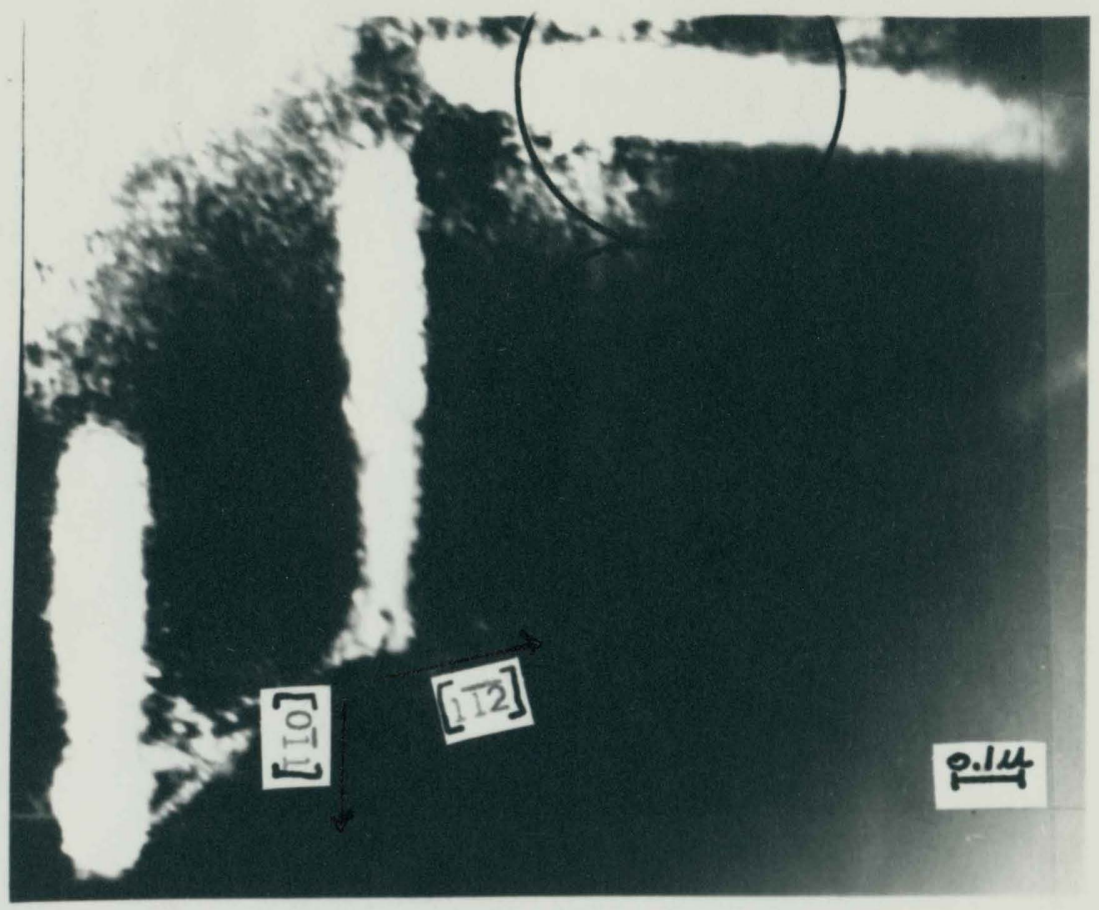

Fiqure 26. Electron micrograph $(74,000 \mathrm{X})$ of an Alnico 6 sample heat treated with a magnetic field and furnace-cooled. The identity of the three lens-shaped structures is unknown.
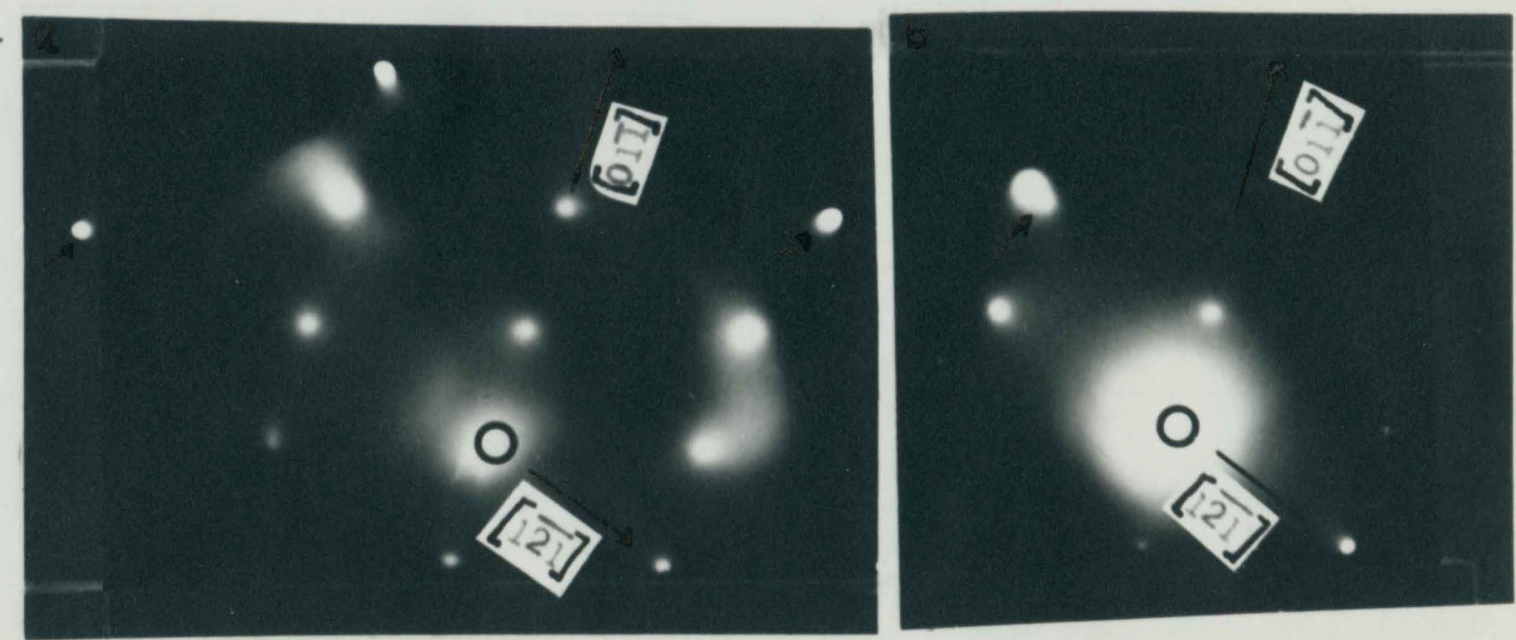

Figure 27. Electron diffraction patterns of (a) the $\alpha_{1}+\alpha_{2}$ phases and (b) the $\alpha_{1}+\alpha_{2}$ phases and one of the lens-shaped structures in figure 26. 
CHAPTER V

DISCUSSION OF THE RESULTS

\section{CONCLUSIONS}

The crystal structure of the $\alpha_{\gamma}$ phase in Alnico 6 is body-centered cubic, as was found in Alnico 5 and Alnico 8 by Koch et al (4). In addition, this study indicates that the phase is ordered in Alnico 6. The $\alpha_{\gamma}$ phase is probably ordered in the other Alnico alloys, but no information about ordering in these alloys was found for the $\alpha_{\gamma}$ phase. This lack of information is probably due to the fact that most work with Alnico alloys is concerned with the $\alpha_{1}+\alpha_{2}$ phases, because these phases are responsible for the excellent magnetic properies of Alnico alloys. A corabination of $X$-ray and electron diffraction was used to determine the lattice parameter of the $\alpha_{\gamma}$ phase.

Only one of the X-ray diffraction patterns is definitely of one phase. This is the pattern of the sample water-quenced from $1250^{\circ} \mathrm{C}$. Froin this pattern it was determined that the lattice parameter of the $\alpha$ phase is $2.87 \AA$.

The other two $X$-ray diffraction patterns were taken from samples containing two phases-- $\alpha+\alpha_{\gamma}$ and $\alpha_{1}+\alpha_{2}$. In each case the $x$-ray diffraction pattern was essentially one of a single phase, indicating that the lattices of both phases in a sample are coherent. A lattice parameter of $2.87 \AA$ was found in each case, but whether the lattice parameter applied to just one or both of the phases could not be 
determined from the X-ray patterns. .

Since no difference was found in the lattice parameters of $\propto$ and $\alpha_{1}$ in Alnico 5 and Alnico 8 , it was assumed that there is no difference between the lattice parameters of these phasos in Alnico 6 . This assunption provides a link between the $\mathrm{X}$-ray and electron diffraction work. To within the accuracy of the electron diffraction measurements, no.difference was found in the lattice parameters of the $\alpha_{1}, \alpha_{2}$, and $\alpha_{\gamma}$ phases.

In summary, the crystal structure of the $\alpha_{\gamma}$ phase in Alnico 6 is ordered body-centered cubic, with a lattice parameter of about $2.87 \AA$. The degree of ordering in the $\alpha_{\gamma}$ phase is less than that in the $\alpha_{1}$ phase. The lattice parameter of the $\propto, \chi_{1}$, and $\alpha_{2}$ phases is also about $2.87 \AA$; and the lattices of these phases are coherent with each other.

\section{SUGGEST IONS FOR FURTHER STUDY .}

Soveral abservations in this study can not be explained readily. Especially puzzling are:

(1) the high dislocation density in the $\alpha_{\gamma}$ phase,

(2) the twinning in the $\alpha_{\gamma}$ formed in a manetic field,

(3) and the identity of the lens-shaped particles.

Whether or not the $\gamma_{1} \rightarrow \alpha_{\gamma}$ transformation occurs martensitically may have a bearing on (1) and (2). X-ray or electron diffraction studies could be made to determine the habit plans and orientation relationship between the $\gamma_{1}$ and $\alpha_{\gamma}$ phases. The habit plane and orientation relationship could be compared to those predicted for a martensitio 
transformation by Bowles and Mackenzie (20) and Wechsler, Lieberman, and Read (20). A good agreement between the experimentally deternined habit plane and orientation relationship and those predicted by theory would Indicate a martensitic transformation, though not conclusively. Also samples could be polished prior to the heat treatment at $1000^{\circ} \mathrm{C}$. After cooling tho samples below the $\gamma_{1} \rightarrow \alpha_{\gamma}$ transformation temperature, surface relief effects would be in the $\gamma_{1}-\alpha_{\gamma}$ region of the samples if the transformation occurred martensitically. Electron microprobe studies may be able to Identify the lens-shaped particles. 


\section{REFERENCES}

1. K. J. de Vos, Magnetism_and Metallurgy (Acaderic Press, New York, 1969) Vol. 1, p. 473.

2. U.S. Pat. 2,578,407, Brit. Pat. 660,580; cited in K. J. de Vos, Magnetism_and Metallurgy, p. 473.

3. Brit. Pat. 634,686; 634,700; 660,591; 660,592; 640,886; and 639,488 ; cited in K. J. de Vos, Magnetism and Metallurqy, p. 473.

4. A. J. J. Koch et al., Proceedings of the Conference on Magnetisn and Magnetic Materials, Boston, 1956 (American Institute of Electrical Engineers, New York, 1957), AIEE Spec. Publ. T-91, p. 173.

5. Metals Handbook (American Society for Metals, 1961) Vol. 1, p. 782.

6. E. C. Stoner and E. P. Wohlfarth, Nature 160, 650 (1947); cited in C. Kittel and J. K. Galt, Solid State Physics (Academic Press, Inc., New York, 1956) Vol. 3, p. 437.

7. A. H. Goisler, Phys. Rev. 81, 478 (1951).

8. R. D. Heidenreich and E. A. Nesbitt, J. Appl. Phys. 23, 366 (1952).

9. C. Kittel et al., Phys. Rev. 77, 839 (1950).

10. J. W. Cahn, J. Appl: Phys. 34, 3581 (1963).

11. K. J. de Vos, "The Relationship between Microstructure and Magnetic Properties of Alnico Alloys", Ph.D. Thesis, Eindhoven University, 1966; cited in K. J. de Vos, Magnetism and Metallurgy, p. 473.

12. J. Dash, "Electron Transmission and Diffraction Observations of the Microstructure of Alnico Alloys", Ph.D. Thesis, Pa. State University, 1966.

13. C. A. Julien and F. G. Jones, J. Appl. Phys. 36, 1176 (1965).

14. M. G. v.d. Steeg and K. J. de Vos, Z. Angew Phys. 17, 98 (1964), cited in C. A. Julien and F. G. Jones, J. Appl. Phys. 36, 1176 (1965).

15. C. T. Ulzey, Phys. Rev. 11, 40 (1918); cited in A. H. Compton and S. K. Allison, $X$-rays in Theory and Experiment Nostrand Company, Inc., Princeton, N.J., 1935), p. 38.

16. B. D. Cullity, Elements of X-ray Diffraction (Addison-Hesley Publishing Co., Inc., Readings, Mass., 1956), p. 465. 
17. J. Dash, Private Communication (1970).

18. C. Bronner et al., Cobalt 36, 123 (1967).

19. I. Pfoiffer, Cobalt 44, 115 (1969).

20. C. $M$. Wayman, Introduction to the Crystallography of Martensitic Iransformations (The Machillian Company, New York, 1964).

21. K. R. Satyanarayan et al., Acta Met. 16, 877 (1968).

\section{OTHER SOURCES}

K. W. Andrews et al., Interpretation of Electron Diffraction Patterns

(Plenum Press, New York, 1967).

P. B. Hirsch et al., Electron Microscopy of Thin Crystals (Butterworths, London, 1965 ). 